\title{
Functional and structural imaging of phototrophic microbial communities and symbioses
}

\author{
Michael Kühl ${ }^{1, *}$, Lubos Polerecky $^{2}$ \\ ${ }^{1}$ Marine Biological Laboratory, Department of Biology, University of Copenhagen, Strandpromenaden 5, \\ 3000 Helsingør, Denmark \\ ${ }^{2}$ Max-Planck-Institute for Marine Microbiology, Celsiusstrasse 1, 28359 Bremen, Germany
}

\begin{abstract}
In recent years, new imaging methods for mapping microhabitats, solute concentrations, microbial activity and photopigment content have been developed and increasingly applied in different areas of aquatic microbial ecology and biogeochemistry. Such techniques exhibit a spatial resolution similar to that of microsensors, but allow for instantaneous mapping of the 2-dimensional distribution and dynamics of solute and pigment concentrations over areas ranging from $\mu^{2}$ to several $\mathrm{cm}^{2}$. Methods have been developed for imaging $\mathrm{O}_{2}$ and $\mathrm{CO}_{2}$ concentrations as well as $\mathrm{pH}$ with optical sensor foils (i.e. planar optodes), and for combined imaging of photopigments and photosynthetic activity via variable chlorophyll fluorescence. More recently, hyperspectral imaging has been employed to identify pigment content in individual cells and to visualize the spatial organization of functional groups in photosynthetic microbial communities. We give an overview of these emerging methods with a range of illustrative examples to demonstrate how they can provide useful information in functional and structural studies of a variety of aquatic microbial communities, such as sediments, biofilms, coral tissues or photosynthetic mats.
\end{abstract}

KEY WORDS: Imaging - Microenvironment - Photosynthesis · Oxygen · Planar optodes · Hyperspectral · Variable chlorophyll fluorescence $\cdot$ Photopigments

\section{INTRODUCTION}

Electrochemical and optical microsensors are powerful and minimally invasive tools for studying the microenvironment and activity of microorganisms in their natural habitat at a high spatio-temporal resolution (reviewed in Revsbech \& Jørgensen 1986; Kühl \& Revsbech 2001, Revsbech 2005, Kühl 2005). Since their introduction to environmental microbiology in the 1970s, the use of microsensors has completely changed our view of the function of microbial communities and how microbial activity is regulated by biotic and abiotic factors. However, it is important to realize that microsensor measurements represent a limited number of point measurements that essentially describe complex and inherently heterogeneous microbial communities from a 1-dimensional point of view (e.g. Jørgensen \& Des Marais 1990). Consequently, it is often rather difficult, if not impossible, to extrapolate from such measurements towards quantitative relationships in 3 dimensions at larger scales. Structural imaging and spatial reconstruction, as achieved by confocal microscopy and advanced electron microscopy methods, show that most microbial communities are complex 3-dimensional structures - or rather 4-dimensional, as the spatial structure changes dynamically over time-in which the microenvironments are expected to exhibit similarly complex and dynamic heterogeneities. Consequently, there is a need for techniques which can reveal this spatio-temporal patchiness in microenvironmental conditions and provide information on microbial activity and identity while leaving the community largely intact.

In recent years, new imaging techniques have been developed for mapping the distribution of key parameters $\left(\mathrm{O}_{2}\right.$ and $\mathrm{CO}_{2}$ concentrations, $\left.\mathrm{pH}\right)$ with planar sensor 
foils (i.e. planar optodes) in laboratory and in situ applications (e.g. Liebsch et al. 2000, Glud et al. 1999, 2001, Zhu et al. 2005, 2006, Stahl et al. 2006, Kühl et al. 2007). There are also other types of functional and structural imaging methods, such as variable chlorophyll fluorescence imaging of photosynthesis (e.g. Grunwald \& Kühl 2004, Ralph et al. 2005), hyperspectral (HS) imaging of photopigments (Bachar et al. 2008, M. Kühl et al. unpubl., L. Polerecky et al. unpubl.), and nuclear spin magnetic resonance (NMR) imaging of porosity and diffusivity (e.g. Wieland et al. 2001), that are just beginning to be applied in environmental microbiology. Here, we give an overview of recent developments in $\mathrm{O}_{2}$, variable fluorescence, and HS imaging. The aim is to inform aquatic microbiologists about fascinating new experimental possibilities for imaging pigment distributions, the activity of microbes and their physico-chemical microenvironments. We present a somewhat detailed description of the different techniques to facilitate better appreciation of their respective strengths and weaknesses, and illustrate their use in aquatic microbiology by providing a range of examples, focusing primarily on phototrophic communities. We do not address irreversible gel-sampling techniques, which can also be used to measure 2-dimensional distributions of solutes and solute fluxes (Davison et al. 2000) and which are excellent techniques to combine with the imaging techniques discussed here.

\section{$\mathrm{O}_{2}$ IMAGING WITH PLANAR OPTODES}

\section{Background}

Development of sensors for the optical detection and quantification of chemical species is one of the most active research areas within analytical chemistry (Wolfbeis 2003, 2004). The primary challenge is to develop indicator dyes ('indicator chemistry') that exhibit reversible changes in their optical properties, i.e. luminescence or absorbance, as a function of analyte concentration. In recent years, such sensors have found widespread application in the environmental sciences. By depositing the sensing chemistry at the measuring tip of tapered optical fibers, fiber-optic microsensors (i.e. microoptodes) can be constructed. In combination with micromanipulators for positioning and the necessary optoelectronic instrumentation, such microoptodes allow high spatial resolution measurements of key solutes (e.g. $\mathrm{O}_{2}, \mathrm{pH}$ and $\mathrm{CO}_{2}$ ) in a broad range of environmental samples in the laboratory and in situ (reviewed in Holst et al. 2000, Kühl 2005).

By immobilizing the optical indicator dye on a transparent carrier foil or a thin glass substrate instead of at a fiber tip, planar sensors (i.e. planar optodes) can be made. When combined with special imaging systems (e.g. Holst et al. 1998, Zhu et al. 2005, Oguri et al. 2006), planar optodes allow instantaneous 2-dimensional mapping of parameters such as $\mathrm{O}_{2}$ and $\mathrm{pH}$ in the sample. Planar optodes were first introduced to the environmental sciences by Glud et al. (1996, 1999), and were first applied in studies of 2-dimensional distributions of $\mathrm{O}_{2}$ and its dynamics in sediments and microbial mats. In the past few years, this methodology has undergone extensive development and has been successfully employed in many laboratory and in situ studies, ranging from investigations of microbial activity in biofilms and sediments to applications studying the effects of bioirrigation, bioturbation or $\mathrm{O}_{2}$ loss from plant roots on sediment biogeochemistry. Here, we give an overview of planar $\mathrm{O}_{2}$ optodes, their function, construction and application in aquatic microbiology.

\section{Optical sensing of $\mathrm{O}_{2}$}

$\mathrm{O}_{2}$ can be measured optically using different luminescent indicator dyes that exhibit a dynamic quenching of their luminescence intensity, $I$, and luminescence lifetime (also called decay time), $\tau$, in the presence of $\mathrm{O}_{2}$. When an indicator dye molecule is excited by an energy-rich photon (e.g. in the blue spectral region), the molecule would, under anoxic conditions, return to its ground state by emitting a longer wavelength photon (e.g. in the red region). If $\mathrm{O}_{2}$ is present however, it can collide with the excited indicator molecule, transferring excitation energy to $\mathrm{O}_{2}$ and causing the formation of singlet oxygen. This, in turn, is rapidly converted back to $\mathrm{O}_{2}$ via heat dissipation. Such quenching is more efficient the more $\mathrm{O}_{2}$ is around, and the relationship between indicator luminescence and $\mathrm{O}_{2}$ concentration can be described by the Stern-Volmer equation (Wolfbeis 2003):

$$
\frac{I_{C}}{I_{0}}=\frac{\tau_{C}}{\tau_{0}}=\frac{1}{1+K_{S V} \times C}
$$

where $c$ is the $\mathrm{O}_{2}$ concentration, $I_{0}$ and $\tau_{0}$ are the luminescence intensity and life-time of the indicator in the absence of $\mathrm{O}_{2}$, respectively, and $K_{S V}$ is a characteristic quenching coefficient of the indicator.

Optical $\mathrm{O}_{2}$ indicators exhibit the highest sensitivity at low $\mathrm{O}_{2}$ concentrations. Typical $\mathrm{O}_{2}$ indicators only show significant interference with sulfur dioxide $\left(\mathrm{SO}_{2}\right)$, which is not present in most environmental applications. Furthermore, in contrast to electrochemical sensors, $\mathrm{O}_{2}$ optodes are not affected by hydrogen sulfide $\left(\mathrm{H}_{2} \mathrm{~S}\right)$. Furthermore, $\mathrm{O}_{2}$ optodes do not consume oxygen and thus do not introduce stirring artifacts to the measured signal. 
When an indicator is immobilized in a matrix material, its luminescence as a function of $\mathrm{O}_{2}$ often exhibits non-ideal behavior, which can be described by a modified Stern-Volmer-like relation (Klimant et al. 1997):

$$
\frac{I_{C}}{I_{0}}=\frac{\tau_{C}}{\tau_{0}}=\frac{1-\alpha}{1+K_{S V} \times C}+\alpha
$$

where $\alpha$ is a non-quenchable fraction of the indicator luminescence, typically around 0.1 to 0.2 . The $\mathrm{O}_{2}$ concentration $(c)$ can thus be expressed as:

$$
C=\frac{\left(I_{0}-I_{C}\right)}{K_{S V} \times\left(I_{C}-I_{0} \alpha\right)}=\frac{\left(\tau_{0}-\tau_{c}\right)}{K_{S V} \times\left(\tau_{c}-\tau_{0} \alpha\right)}
$$

For a given mixture of the indicator and the matrix material, $\alpha$ is usually constant over the dynamic range of $\mathrm{O}_{2}$ concentrations present in the sample, and Eq. (2) accurately describes the non-linear behavior of $I$ or $\tau$ versus $c$. The parameter $\alpha$ can be determined from the measurement of luminescence at 3 defined $\mathrm{O}_{2}$ concentrations (e.g. $0, c_{1}=20 \% \mathrm{O}_{2}$ saturation, and $c_{2}=100 \%$ $\mathrm{O}_{2}$ saturation). First, the quenching constant $K_{S V}$ can be determined as:

$K_{S V}=\frac{I_{0}\left(C_{2}-C_{1}\right)-\left(I_{1} C_{2}-I_{2} C_{1}\right)}{\left(I_{1}-I_{2}\right) \times C_{1} \times C_{2}}=\frac{\tau_{0}\left(C_{2}-C_{1}\right)-\left(\tau_{1} C_{2}-\tau_{2} C_{1}\right)}{\left(\tau_{1}-\tau_{2}\right) \times C_{1} \times C_{2}}$

Subsequently, $\alpha$ is calculated as:

$$
\alpha=\frac{I_{1}\left(1+K_{S V} C_{1}\right)-I_{0}}{I_{0} \times K_{S V} \times C_{1}}=\frac{\tau_{1}\left(1+K_{S V} C_{1}\right)-\tau_{0}}{\tau_{0} \times K_{S V} \times C_{1}}
$$

Once $\alpha$ has been determined, calibration of optical $\mathrm{O}_{2}$ sensors can be done by a simple 2-point calibration, e.g. by measuring $I$ or $\tau$ at anoxia and at a known $\mathrm{O}_{2}$ concentration.

\section{Sensor materials}

The sensitivity and dynamic range of planar $\mathrm{O}_{2}$ optodes can be tailored by the appropriate choice of $\mathrm{O}_{2}$ indicator type and immobilization matrix. The two types of $\mathrm{O}_{2}$ indicators most commonly used (Papkovsky 2004, O'Donovan et al. 2005, Wolfbeis 2005) are (1) metalloorganic complexes of ruthenium(II), which are excited by blue light ( 440 to $480 \mathrm{~nm}$ ) and emit red light ( $\lambda_{\max } \sim$ $610 \mathrm{~nm}$ ), and (2) metallo-porphyrines with platinum or palladium as the central atom, which are excited by UV (395 to $405 \mathrm{~nm}$ ) or blue-green (500 to $550 \mathrm{~nm}$ ) light and emit red light $\left(\lambda_{\max } \sim 650 \mathrm{~nm}\right)$. Ruthenium(II)-tris-4, 7-diphenyl-1,10-phenanthroline (Ru-dpp), 5,10,15, 20-tetrakis-(2, 3, 4, 5, 6pentafluorphenyl)-porphyrin (PtTFPP), and platinum(II) octaethyl porphyrin (PtOEP) are the most frequently used indicator dyes with planar $\mathrm{O}_{2}$ optodes, albeit PtOEP is rather photolabile.

Ruthenium-dpp-based optodes have a very good photostability and exhibit good and homogeneous sensitivity over a broad dynamic range from 0 to $100 \%$ $\mathrm{O}_{2}$ saturation. PtTFPP- and PtOEP-based planar optodes have a narrower dynamic range (platinumporphyrines: 0 to $250 \%$, and palladium-porphyrines: 0 to $10 \%$ air saturation), but they exhibit a stronger quenching and thus a higher sensitivity and a better signal-to-noise ratio (Oguri et al. 2006). Most recently, Borisov \& Klimant (2007) reported a new ultrabright phosphorescent $\mathrm{O}_{2}$ indicator based on cyclometalated iridium(III) coumarin complexes (Borisov \& Klimant 2007), which are excited with blue light ( 470 nm) and emit in the yellow spectral range (560 to $600 \mathrm{~nm}$ ). Besides extreme brightness, this new indicator also shows a much lower temperature effect on its quenching behaviour than Ru-dpp, PtTFPP and PtOEP. First tests with environmental samples showed excellent performance (M. Stahl et al. unpubl.).

The $\mathrm{O}_{2}$ permeability of the immobilization matrix also affects the sensitivity of planar optodes. An indicator immobilized in a matrix with high $\mathrm{O}_{2}$ permeability exhibits a higher amount of quenching for a given $\mathrm{O}_{2}$ level than when the same indicator is immobilized in a less $\mathrm{O}_{2}$ permeable matrix. Often, the need for good mechanical stability of the matrix is limiting the choice of matrix material. Although silicone has a very high $\mathrm{O}_{2}$ permeability, it is often not a good matrix for planar optode applications due to sub-optimal mechanical stability-especially in applications where samples are moved relative to the planar optode during sampling or positioning of the experimental setup. Instead, polystyrene, which has significantly lower $\mathrm{O}_{2}$ permeability but exhibits good mechanical stability and adhesion to hydrophobic surfaces, is often the preferred immobilization matrix for making planar $\mathrm{O}_{2}$ optodes. Organically modified sol-gels (i.e. Ormosils), whose mechanical stability and $\mathrm{O}_{2}$ permeability can be optimized by tailoring the formation conditions and amounts of precursor material, are also a possible alternative (König et al. 2005).

\section{Construction of planar optodes}

Planar $\mathrm{O}_{2}$ optodes are mostly constructed on a transparent and $\mathrm{O}_{2}$ impermeable carrier, e.g. polyethylene terephthalate foil (Mylar, Goodfellow), onto which a mixture of immobilization matrix and $\mathrm{O}_{2}$ indicator dye (so-called sensor cocktail) is immobilized. A simple knife coating procedure is well-suited for producing relatively small homogeneous sensor foils (of a few $\mathrm{cm}^{2}$ ). However, larger planar optodes are difficult to make using this procedure. For example, non-homogeneous evaporation of the solvent from the knifecoated foil often results in a somewhat thicker rim at the edges of the planar optodes, thereby limiting the 
useful area of the sensor foil. Fast evaporation can also cause tension and formation of fine cracks in the sensor layer. Furthermore, small dust particles in the sensor cocktail can result in the formation of pinholes and stripes in the foil.

A better and easier method for the construction of planar optodes of $10 \times 15 \mathrm{~cm}$ or even larger areas is based on simple dispersion of the sensor cocktail over the carrier foil with a pipette. The coated foil must be kept perfectly horizontal in a small flat chamber, which is closed almost completely with a lid after the deposition of the sensor cocktail. In this way, the evaporation of the solvent can be controlled, preventing the formation of strain and cracks in the foil during the hardening process. The sensor cocktail must be well-mixed and have a rather low viscosity (achieved by the addition of more solvent) to allow construction of homogeneous planar optodes.

A similar method can be applied to immobilize sensor layers directly onto glass substrates such as microscope slides and cover slips. The best adhesion is obtained by making the glass surface hydrophobic by silanization before application of the sensor cocktail. Using spin-coating, sensing layers of only 0.5 to $1.0 \mu \mathrm{m}$ thickness (i.e. planar nano-optodes) can be constructed (Kühl et al. 2007). Such planar $\mathrm{O}_{2}$ nanooptodes exhibit an ideal Stern-Volmer quenching behaviour (see Eq. 1) and a linear temperature dependence of the luminescence intensity or lifetime, which simplifies their calibration and application. These planar nano-optodes can, for example, be used in combination with a confocal microscope (see ' $\mathrm{O}_{2}$ imaging systems and measuring protocols' below).

In luminescence intensity-based $\mathrm{O}_{2}$ imaging, the sensor foil needs to be covered with a black silicone layer, acting as an optical isolation, to prevent reflections of the luminescence generated in the foil from inhomogeneities or optical artifacts behind the foil, which could be misinterpreted as $\mathrm{O}_{2}$ variations. In lifetimebased $\mathrm{O}_{2}$ imaging, this layer is not necessary, provided that the sample does not contain luminescent species or materials with excessively bright luminescence with lifetimes in a similar range as the $\mathrm{O}_{2}$ indicator. This makes it easier to construct and work with the planar optodes, especially with respect to their calibration. The luminescent intensity of the optode can be dramatically enhanced by the addition of inert light scattering particles (e.g. $\mathrm{TiO}_{2}$ ) to the sensor cocktail, resulting in semi-transparent planar optodes (König et al. 2005).

\section{$\mathrm{O}_{2}$ imaging systems and measuring protocols}

Initially, planar $\mathrm{O}_{2}$ optode applications in sediments, biofilms, and microbial mats were based on the use of a simple luminescence intensity imaging system (Glud et al. 1996). A Ru-dpp planar optode in the experimental setup, covered with a black silicone layer for optical isolation, was continuously illuminated from behind by a halogen lamp equipped with a short-pass filter transmitting blue light, and the luminescence intensity was imaged with a sensitive charge-coupled device (CCD) camera equipped with a long-pass filter for detecting the red $\mathrm{O}_{2}$-dependent luminescence from the planar optode.

The development of a modular luminescence lifetime imaging system for $\mathrm{O}_{2}$ planar optodes (Holst et al. 1998) enabled a much more flexible use of planar optodes, including the possibility of using transparent sensor foils, which allow alignment between the sample structure and the measured $\mathrm{O}_{2}$ distribution (Holst \& Grunwald 2001). The imaging system employs a gateable CCD camera (Sensicam-Sensimod, PCO) and an array of blue light-emitting diodes (LEDs) as an excitation light source. The timing of the image acquisition by the camera and the excitation light pulses are controlled by a pulse-delay trigger unit. By varying the timing of image acquisition relative to the excitation light pulses, it is possible to acquire (1) normal luminescence intensity images, i.e. images recorded while LEDs are on, (2) lifetime-proportional images, i.e. the ratio of images acquired during illumination and immediately after the eclipse of illumination, and (3) luminescence lifetime images, derived from 2 or 3 intensity images acquired in different time windows after the eclipse of illumination (see Holst et al. 1998, Holst \& Grunwald 2001 for additional details). A similar system, but employing a different hardware, was developed by Oguri et al. (2006).

Instead of lifetime imaging, the $\mathrm{O}_{2}$ dependent emission of the indicator can also be referenced against the emission from an inert luminescent dye. This way, most of the potential artifacts arising from luminescence intensity measurements can be referenced out by calibrating the ratio of the $\mathrm{O}_{2}$-dependent luminescence over the reference luminescence against $\mathrm{O}_{2}$ concentration. Both the indicator and reference dyes need to be immobilized with a defined molar ratio in the same matrix. Optimally, both dyes should be excited in the same spectral range, and the ratiometric referencing can be done either by spectral (facilitated by distinct emission spectra of the dyes) or temporal (enabled by distinct luminescence lifetimes of the dyes; Klimant 1997, Huber et al. 2000) separation of the 2 luminescence signals. To our knowledge, such ratiometric $\mathrm{O}_{2}$ imaging has not yet been applied in environmental applications of planar optodes. However, it has recently been used in first applications of $\mathrm{O}_{2}$-sensitive nano-particles for ratiometric mapping of $\mathrm{O}_{2}$ on a confocal laser scanning microscope (M. Staal et al. unpubl. 
data), and we are currently implementing this approach for use with planar $\mathrm{O}_{2}$ nano-optodes.

In most laboratory applications of planar $\mathrm{O}_{2}$ optodes, the sensor foil is fixed in a given position, e.g. on the inner wall of a flow chamber, and cannot be moved to different points within a sample. To enable such repetitive measurements, an endoscope system for planar optodes was developed by Holst et al. (1999). A similar 'inverted periscope' approach was later used to design an underwater module (Glud et al. 2001), which has been applied for in situ $\mathrm{O}_{2}$ imaging in coastal and deep-sea sediments (e.g. Wenzhöfer \& Glud 2004, Glud et al. 2005). The module consists of a pressureand water-tight cylinder which contains the camera, electronics and an array of blue LEDs. The LED excitation is coupled to an optical periscope head which is coated with a planar optode on one side and can be inserted into the sediment using a motorized positioning device. The design of the periscope head mini- mizes disturbance and mechanical smearing in front of the planar optode (Glud et al. 2001), and the device can be mounted on different underwater measuring platforms such as ROV's or benthic landers.

$\mathrm{O}_{2}$ imaging has also been implemented in microscopic applications, where an ultrabright blue LED (e.g. from Luxeon or Nichia) and the CCD camera are, respectively, connected to the excitation light port and the C-mount of a standard epifluorescence microscope (Fig. 1). Appropriate filter-combinations can then be implemented as normal epifluorescence filter blocks on the microscope. Such a configuration was adapted to a confocal microscope, which allowed the combined mapping of bacterial biomass and $\mathrm{O}_{2}$ concentrations at the base of a biofilm (Kühl et al. 2007).

An important aspect of $\mathrm{O}_{2}$ imaging is proper calibration of the sensor foils. Normally, this is achieved by filling the experimental chamber containing a mounted planar optode with $\mathrm{N}_{2}$ or Ar-flushed water
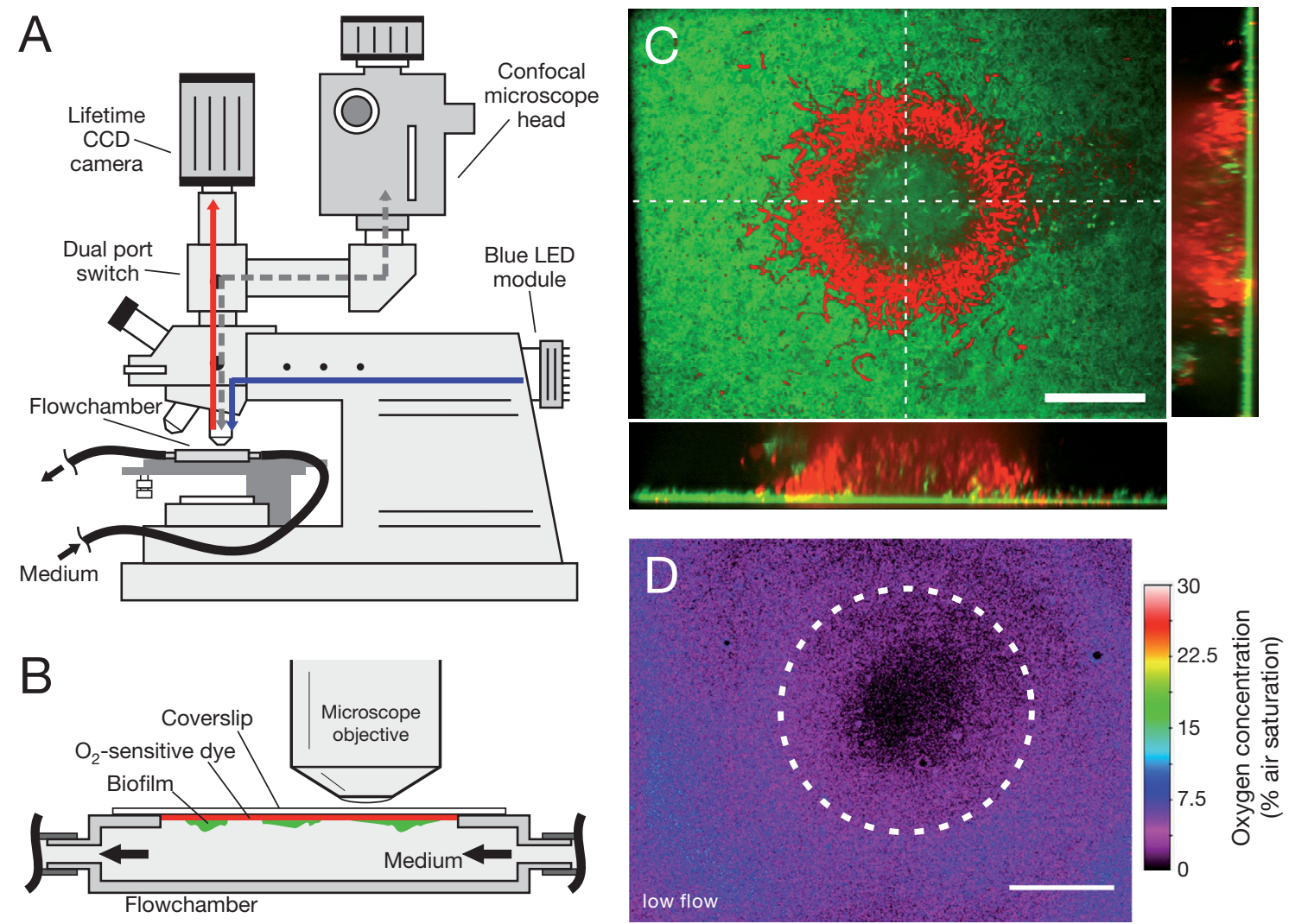

Fig. 1. Combined microscopic imaging of the structure and $\mathrm{O}_{2}$ distribution in a biofilm growing on top of a transparent $<1 \mu \mathrm{m}$ thick planar $\mathrm{O}_{2}$ optode. (A) Oxygen imaging was done with a custom-built fluorescence lifetime imaging system mounted onto a spinning disk laser confocal microscope (Ultraview LCI, Perkin Elmer). (B) The planar optode was used as a lid in a small flow chamber for studying biofilm growth. (C) Z-stack projection and vertical slices (shown as side panels to the right and below the projection) reconstructed from optical sectioning through a cell cluster of a GFP-mutant Pseudomonas putida (green) and heterotrophic contaminant bacteria stained with a DNA stain (Syto 60, Molecular Probes, Invitrogen) (red), as imaged through the planar optode. (D) Corresponding $\mathrm{O}_{2}$ distribution showing strong oxygen depletion under the biofilm cell cluster. Scale bars $=40 \mu \mathrm{m}$. The data show pronounced heterogeneity at the cellular level, and that low $\mathrm{O}_{2}$ conditions can prevail below biofilm structures and cell clusters as small as 80 to $100 \mu \mathrm{m}$ in diameter (reproduced from Kühl et al. 2007) 
$\left(0 \% \mathrm{O}_{2}\right)$ and with air-flushed water $\left(20 \% \mathrm{O}_{2}\right)$, either before or after the experiment. After the sample is placed in the chamber, $\mathrm{O}_{2}$ images acquired during experiments can be calibrated using a pixel-by-pixel calibration procedure based on Eqs. (1-5), which yields the most accurate calibration. If the planar optode is homogeneous, it is also possible to calibrate from readings on part of the acquired images, e.g. from average pixel values obtained from sensor areas exposed to ambient water of known $\mathrm{O}_{2}$ content above the sample surface and those located in anoxic parts of the sample. Such a calibration procedure works especially well with planar $\mathrm{O}_{2}$ nano-optodes, where tests showed no significant difference when comparing the pixel-by-pixel calibration to that based on average pixel values (Kühl et al. 2007).

When interpreting the results, it is also important to align the acquired $\mathrm{O}_{2}$ images with the structure of the studied system. For example, the position of the sediment-water interface needs to be determined to accurately calculate diffusive fluxes from the $\mathrm{O}_{2}$ concentration images. Such alignment is facilitated by using transparent or semi-transparent planar $\mathrm{O}_{2}$ optodes (Holst \& Grunwald 2001). With semi-transparent sensor foils, the sample topography against the planar optode can be determined by shining white light directly towards or from behind the optode. When measuring with planar optodes covered by an optical isolation layer, it is impossible to directly observe the sample topography. However, it is possible to visualize it chemically, e.g. by adding crystals of a strong reducing agent, such as sodium dithionite, to the surface. The strong local $\mathrm{O}_{2}$ depletion created by this agent can then be monitored on the $\mathrm{O}_{2}$ optode and used to interpolate the surface topography (Glud et al. 1996).

\section{Software for $\mathrm{O}_{2}$ imaging and $\mathrm{O}_{2}$ image analysis}

Camera manufacturer-provided software is usually sufficient for the basic acquisition of luminescence images in intensity-based $\mathrm{O}_{2}$ imaging. Imaging employing lifetime-based and ratiometric principles requires image acquisition and control of the excitation light source and other hardware components (e.g. filters) in special timing protocols (see previous section), which has been made possible by specially developed measuring software (Holst \& Grunwald 2001, Polerecky 2005, L. Polerecky unpubl.). Basic image analysis such as calculation of $\mathrm{O}_{2}$ images from the raw images based on Eqs. (1) to (5), extraction of pixel averages or profiles from the $\mathrm{O}_{2}$ images or overlay of $\mathrm{O}_{2}$ images with the sample topography outline-can be done with freely available software (Polerecky 2005, L. Pol- erecky unpubl.). Additionally, software implementing more advanced routines, such as pixelwise calculation of rates based on the spatial (Bachar et al. 2008) or temporal (Polerecky et al. 2005) derivatives of $\mathrm{O}_{2}$ images, or for the analysis of extensive $\mathrm{O}_{2}$ image series (Polerecky et al. 2006), is also available from the authors.

\section{Planar $\mathrm{O}_{2}$ optode studies of photosynthetic microbial communities}

Planar $\mathrm{O}_{2}$ optodes have been employed in a wide range of laboratory and in situ studies of $\mathrm{O}_{2}$ distributions in coastal and deep sea sediments (e.g. Glud et al. 1996, 2001, 2005, Oguri et al. 2006). They have also been used to quantify the distribution of $\mathrm{O}_{2}$ consumption rates in permeable sediments (Polerecky et al. 2005, Franke et al. 2006, Billerbeck et al. 2006, Werner et al. 2006), and have proven a powerful tool to visualize and quantify the effects on the $\mathrm{O}_{2}$ dynamics and biogeochemical zonation in sediments of advective transport (Precht et al. 2004, Franke et al. 2006), fauna bioturbation and bioirrigation (Wenzhöfer \& Glud 2004, Polerecky et al. 2006, Volkenborn et al. 2007), or radial $\mathrm{O}_{2}$ loss from plants (Jensen et al. 2005, Frederiksen \& Glud 2006).

Planar $\mathrm{O}_{2}$ optodes are also an excellent tool for studying photosynthesis and respiration in aquatic microbial communities such as microbial mats and biofilms (Glud et al. 1999, Bachar et al. 2008), where rates of net $\mathrm{O}_{2}$ production and consumption can be spatially resolved (Fig. 2). Furthermore, they allow monitoring of the photosynthetic $\mathrm{O}_{2}$ production of extremely shade-adapted endolithic phototrophs, with the possibility to align activity areas to distinct spatial zones in coral skeletons (Fig. 3; Kühl et al. 2008). In principle, planar optodes can also resolve distributions of gross photosynthetic activity (e.g. Glud et al. 1999) using the same light-dark shift methodology developed for $\mathrm{O}_{2}$ microsensors (Revsbech \& Jørgensen 1983). However, when using relatively thick planar $\mathrm{O}_{2}$ optodes, especially those coated with black silicone for optical isolation, the sensor layer will act as an $\mathrm{O}_{2}$ reservoir, masking the true $\mathrm{O}_{2}$ dynamics and causing diffusive smearing of its spatial distribution. The most accurate imaging of gross photosynthesis thus requires thin planar $\mathrm{O}_{2}$ optodes, e.g. planar nano-optodes (Kühl et al. 2007).

\section{Planar optode imaging of other parameters}

Besides $\mathrm{O}_{2}$, planar optodes for various other parameters, such as pH and $\mathrm{CO}_{2}$, have been developed and applied in sediments using both ratiometric (Zhu 

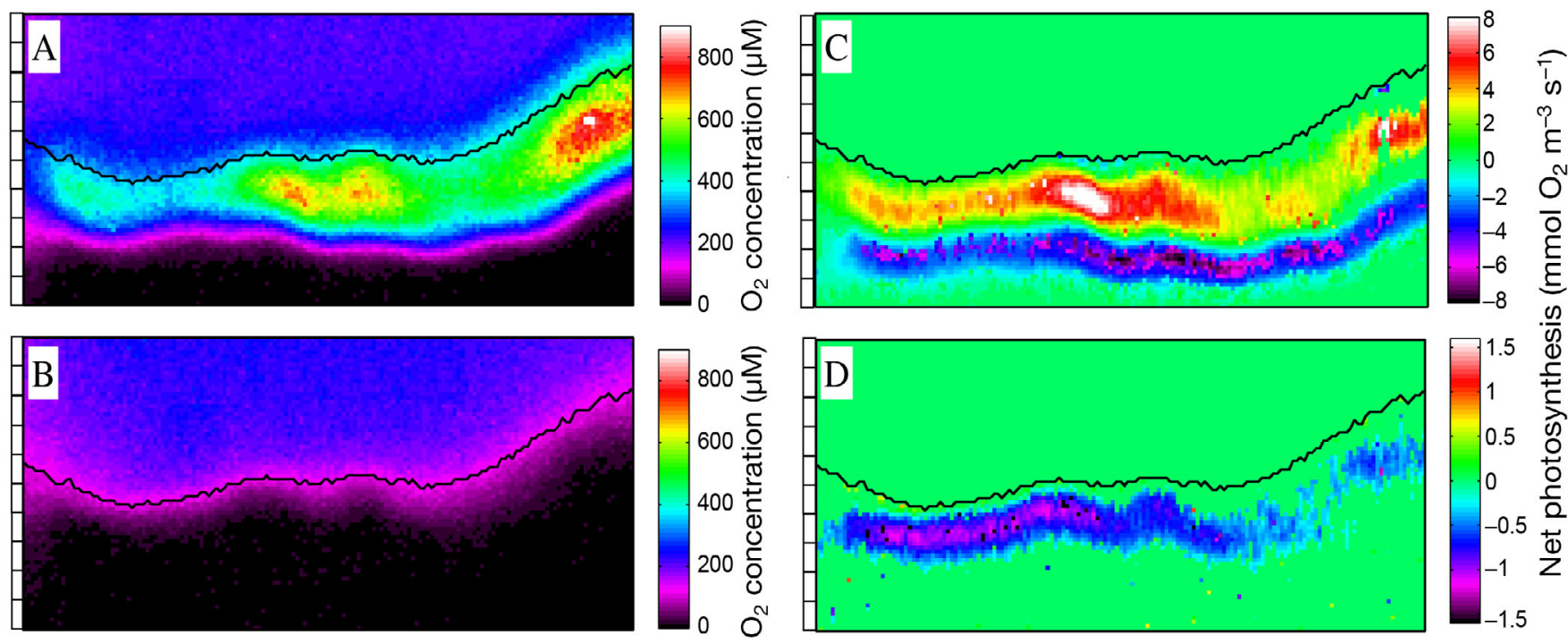

Fig. 2. Imaging of $\mathrm{O}_{2}$ concentrations and photosynthesis in a microbial mat obtained by a planar $\mathrm{O}_{2}$ optode. (A,B) Steady state $\mathrm{O}_{2}$ distributions across a vertical section of the mat. $(\mathrm{C}, \mathrm{D})$ Corresponding rates of net photosynthesis (NP), calculated from the $\mathrm{O}_{2}$ images using a simple diffusion-reaction model $\left(\mathrm{NP} \approx-D \partial^{2}\left(\mathrm{O}_{2}\right) / \partial z^{2}\right.$, where $D=1.82 \times 10^{-9} \mathrm{~m}^{2} \mathrm{~s}^{-1}$ is the diffusion coefficient of $\mathrm{O}_{2}$ in the mat, and $z$ represents depth). Positive NP values indicate net $\mathrm{O}_{2}$ production, while negative values indicate net $\mathrm{O}_{2}$ consumption. (A,C) Mat illuminated by visible light (400 to $700 \mathrm{~nm}$ ) of irradiance $\sim 200 \mu \mathrm{mol}$ photons $\mathrm{m}^{-2} \mathrm{~s}^{-1}$, and $(\mathrm{B}, \mathrm{D})$ dark conditions. Scale bar in $\mathrm{mm}$ is shown to the left, color-bar to the right of the images. Note different color scales of the light and dark $\mathrm{O}_{2}$ turnover rates in $\mathrm{C}$ and $\mathrm{D}$. The data show how planar optodes enable microscale quantification of photosynthesis and respiration in heterogeneous samples exhibiting strong biogeochemical gradients. See Glud et al. (1999) and Bachar et al. (2008) for more details

et al. 2005, 2006) and lifetime imaging systems (Liebsch et al. 2000, Stahl et al. 2006). While some of these studies showed pronounced light-dependent $\mathrm{pH}$ dynamics in sediments with microphytobenthos, a more detailed application of these sensors for photosynthesis studies still needs to be realized. Most recently, combined planar sensors for simultaneous imaging of $\mathrm{pH}$ and $\mathrm{O}_{2}$ have also been used for sediment studies (Schröder et al. 2007). Other combined sensor materials and measuring systems have been developed (Nagl \& Wolfbeis 2007), e.g. for simultaneous imaging of $\mathrm{O}_{2}$ and temperature (Borisov et al. 2006b), or $\mathrm{O}_{2}$ and $\mathrm{CO}_{2}$ (Borisov et al. 2006a). Such materials should be ideal for investigations of photosynthetic microbial communities and other applications in environmental microbiology.

\section{VARIABLE CHLOROPHYLL FLUORESCENCE IMAGING}

Measurement of variable chlorophyll fluorescence is a powerful method for monitoring the photosynthetic capacity, stress physiology and light acclimation of oxygenic microbial phototrophs, i.e. microalgae and cyanobacteria (Papageorgiou \& Govindjee 2005, Baker 2008). Two different measuring approaches are commonly used in aquatic biology for monitoring photosynthesis via variable chlorophyll fluorescence. One method is based on fast-repetition-rate (FRR) fluorometry, where a sequence of single turnover flashes drives photosystem II (PSII) towards closure, thus allowing the determination of the quantum yield and the functional absorption cross section of PSII under environmental conditions (Falkowski et al. 2005). The other method is based on pulse-amplitude-modulated (PAM) fluorometry, which employs multiple-turnover flashes, determining PSII quantum yields from measurements of chlorophyll fluorescence yield under ambient light and during a strong saturating pulse that completely closes PSII (the so-called saturation pulse method; Schreiber 2005). Kromkamp \& Forster (2003) present a more detailed comparison and discussion of the application of these two methodologies in aquatic biology. To our knowledge, no FRR imaging system is currently available, and in the following we will thus focus on PAM-based imaging systems that have found widespread application in aquatic biology. A more thorough discussion of different variable chlorophyll fluorescence imaging systems can be found in Oxborough $(2004,2005)$ and several chapters in a recent comprehensive review of chlorophyll fluorescence methodology (Papageorgiou \& Govindjee 2005). 

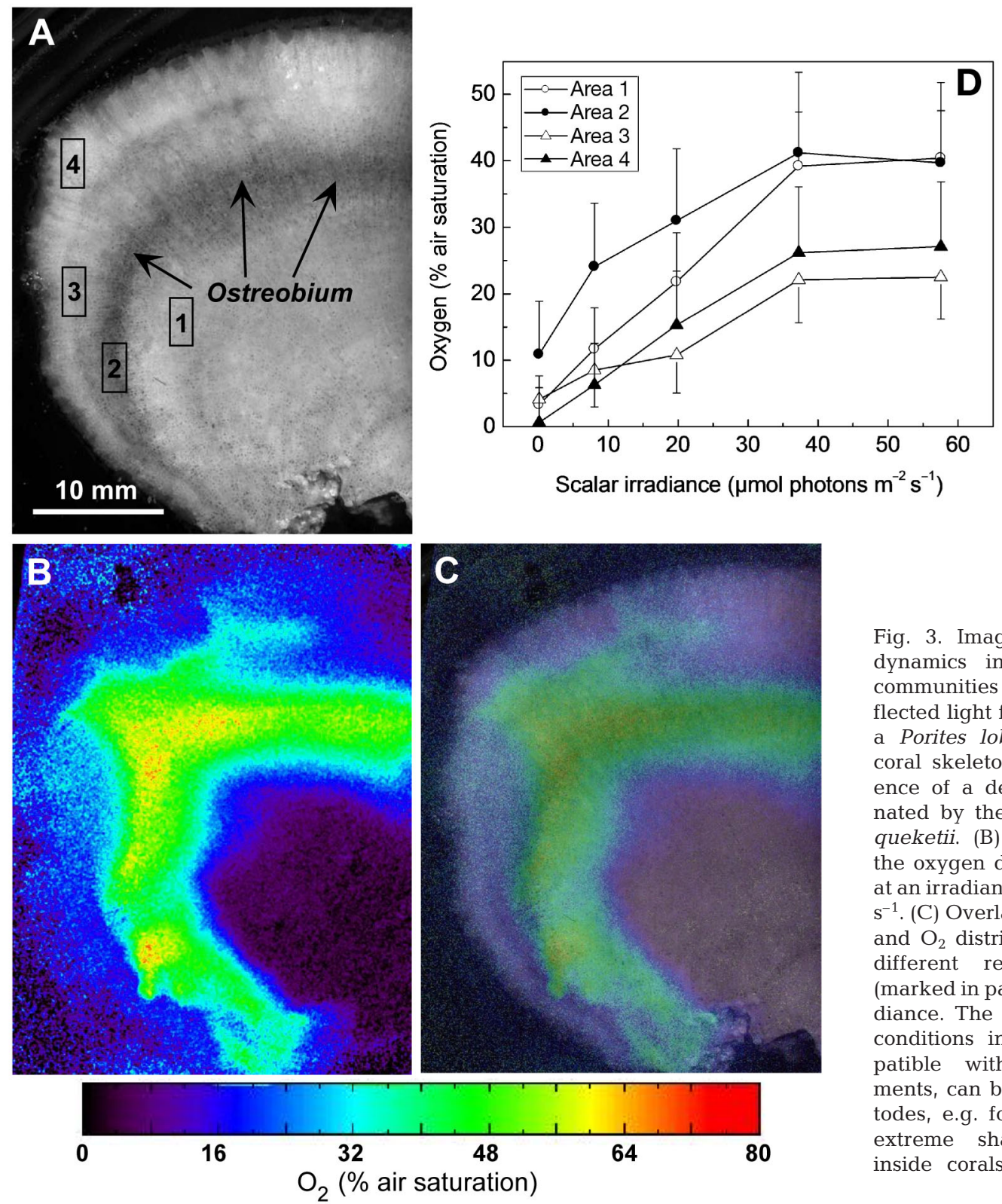

Fig. 3. Imaging of structure and $\mathrm{O}_{2}$ dynamics in endolithic phototrophic communities in coral skeleton. (A) Reflected light from a vertical cut through a Porites lobata colony, showing the coral skeleton structure and the presence of a dense endolith layer dominated by the green alga Oestreobium queketii. (B) Corresponding image of the oxygen distribution in the skeleton at an irradiance of $\sim 37 \mu \mathrm{mol}$ photons $\mathrm{m}^{-2}$ $\mathrm{s}^{-1}$. (C) Overlay of the skeleton structure and $\mathrm{O}_{2}$ distribution. (D) $\mathrm{O}_{2}$ levels in 4 different regions in the skeleton (marked in panel A) as a function of irradiance. The data demonstrate how $\mathrm{O}_{2}$ conditions in solid structures, incompatible with microsensor measurements, can be mapped with planar optodes, e.g. for studying the activity of extreme shade-adapted phototrophs inside corals. Reproduced from Kühl et al. (2008)

\section{Saturation pulse method for measuring PSII quantum yield}

The following rationale (taken from Schreiber et al. 1995) describes how quantum yields of PSII-related photosynthetic electron transport can be determined from the measurements of fluorescence yields with the so-called saturation pulse method. Variable chlorophyll fluorescence under ambient temperature regimes mainly originates from PSII. Absorbed light energy in PSII can be dissipated in 3 ways: (1) it can be converted into chemical energy by initiating a charge separation in PSII that drives electron transport and causes water splitting, (2) it can be dissipated as heat, or (3) it can be emitted as fluorescence. Thus, the sum of quantum yields of photochemistry, $\Phi_{\mathrm{P}}$, fluorescence, $\Phi_{\mathrm{F}}$, and heat dissipation, $\Phi_{\mathrm{D}}$, must equal 1:

$$
\Phi_{\mathrm{P}}+\Phi_{\mathrm{F}}+\Phi_{\mathrm{D}}=1, \text { or } \Phi_{\mathrm{p}}=1-\Phi_{\mathrm{F}}-\Phi_{\mathrm{D}}
$$

In a strong saturating light pulse (s), the PSII reaction center is completely closed $\Phi_{\mathrm{p}}=0$ and thus:

$$
\left(\Phi_{\mathrm{F}}\right)_{\mathrm{S}}+\left(\Phi_{\mathrm{D}}\right)_{\mathrm{S}}=1, \text { or }\left(\Phi_{\mathrm{D}}\right)_{\mathrm{S}}=1-\left(\Phi_{\mathrm{F}}\right)_{\mathrm{S}}
$$

During the saturation pulse, the ratio between heat dissipation and fluorescence is assumed to be unchanged, i.e. 


$$
\left(\Phi_{\mathrm{D}}\right)_{\mathrm{S}} /\left(\Phi_{\mathrm{F}}\right)_{\mathrm{S}}=\Phi_{\mathrm{D}} / \Phi_{\mathrm{F}}
$$

Insertion of Eq. (7) now yields:

$$
\frac{1-\left(\Phi_{\mathrm{F}}\right)_{\mathrm{S}}}{\left(\Phi_{\mathrm{F}}\right)_{\mathrm{S}}}=\frac{\Phi_{\mathrm{D}}}{\Phi_{\mathrm{F}}} \Leftrightarrow \Phi_{\mathrm{D}}=\frac{\Phi_{\mathrm{F}}}{\left(\Phi_{\mathrm{F}}\right)_{\mathrm{S}}}-\Phi_{\mathrm{F}}
$$

Finally, substitution of Eq.(6) yields:

$$
\Phi_{\mathrm{P}}=1-\Phi_{\mathrm{F}}-\left(\frac{\Phi_{\mathrm{F}}}{\left(\Phi_{\mathrm{F}}\right)_{\mathrm{S}}}-\Phi_{\mathrm{F}}\right)=1-\frac{\Phi_{\mathrm{F}}}{\left(\Phi_{\mathrm{F}}\right)_{\mathrm{S}}}=\frac{\left(\Phi_{\mathrm{F}}\right)_{\mathrm{S}}-\Phi_{\mathrm{F}}}{\left(\Phi_{\mathrm{F}}\right)_{\mathrm{S}}}
$$

Thus, it is possible to determine the quantum yield of PSII photochemical activity from measurements of fluorescence yields just before and during a strong saturation pulse.

The maximum quantum yield of PSII-related photosynthetic electron transport is determined from saturation pulse measurements on dark-adapted samples exhibiting a minimal fluorescence yield $\left(F_{0}\right)$, and a maximal fluorescence yield $\left(F_{\mathrm{m}}\right)$, as:

$$
\Phi_{\max }=\frac{F_{\mathrm{m}}-F_{0}}{F_{\mathrm{m}}}=\frac{\Delta F}{F_{\mathrm{m}}}
$$

while the effective quantum yield under known light conditions can be found from the fluorescence yield under ambient light $(F)$ and the maximal fluorescence yield under a saturating pulse $\left(F_{\mathrm{m}}{ }^{\prime}\right)$ as:

$$
\Phi_{\mathrm{PSII}}=\frac{F_{\mathrm{m}}{ }^{\prime}-F}{F_{\mathrm{m}}{ }^{\prime}}
$$

Several other important parameters characterizing photosynthetic performance can be derived from saturation pulse measurements, e.g. measures of the quantum yield of non-photochemical quenching, but here we focus on proxies for photosynthetic activity.

Absolute rates of photosynthetic activity in terms of electron transport (ETR, $\mu$ mol electrons $\mathrm{m}^{-2} \mathrm{~s}^{-1}$ ) can in principle be estimated from effective quantum yield measurements as:

$$
\mathrm{ETR}=k \times \sigma_{\mathrm{II}} \times E_{\mathrm{PAR}} \times \Phi_{\mathrm{PSII}}
$$

where $\sigma_{\text {II }}$ is the effective absorption cross section of PSII, $E_{\mathrm{PAR}}$ is the irradiance of photosynthetically active radiation, and $k$ is a factor describing the distribution of excitation energy between PSII and PSI.

$E_{\mathrm{PAR}}$ can be estimated from simple irradiance or scalar irradiance measurements with commercial instruments (e.g. LiCor, Biospherical Instruments), or in some cases with fiber-optic microprobes (Kühl et al. 1997, Kühl 2005). The factor $k$ is often assumed to be 0.5 , i.e. corresponding to an equal distribution of light energy between PSI and PSII. However, this assumption is problematic because, for example, state shifts caused by changes in the composition of the light harvesting complex and its association with PSII and PSI can strongly affect $k$ (Baker 2008). Although the absorption cross-section of PSII cannot be determined by the saturation pulse method, the functional absorption cross-section of PSII can be measured, e.g. by FRR methods, or estimated by absorption spectroscopy on planktonic samples. The latter is not possible with surface-associated biofilms and tissues with a strong scattering component affecting light attenuation. In practice, many studies therefore simply quantify relative rates of photosynthetic electron transport (rETR) as:

$$
\mathrm{rETR}=A \times E_{\mathrm{PAR}} \times \Phi_{\mathrm{PSII}}
$$

where the absorptivity, $A$, is either set to a constant or estimated from reflectance measurements.

In variable chlorophyll fluorescence imaging, one common estimate of $A$ is derived from imaging the reflectance of red, photosynthetically active light $(R)$ and near infrared (NIR), photosynthetically inactive light $\left(R_{\mathrm{NIR}}\right)$ from a sample according to the formula:

$$
A=1-\frac{R}{R_{\mathrm{NIR}}}
$$

However, this approach only works with thin water layers above the sample, where the differential absorption of red and NIR light in water is negligible.

\section{Variable chlorophyll fluorescence imaging systems and their applications}

Several variable chlorophyll fluorescence imaging systems have been developed (see recent reviews of Nedbal \& Whitmarsh 2005, Oxborough 2005), allowing imaging of the photosynthetic performance of aquatic microbial communities and symbioses at spatial resolutions ranging from single chloroplasts to several $\mathrm{cm}^{2}$. Some of the first applications of this methodology in aquatic microbiology were presented by Oxborough et al. (2000), demonstrating its use for microscopic studies of microphytobenthos photobiology. However, these investigations employed advanced laboratory microscope setups, which is a limiting factor for a more widespread application of variable chlorophyll fluorescence imaging in studies of aquatic systems. Since then, simpler imaging systems suitable for laboratory (e.g. Grunwald \& Kühl 2004, Schreiber 2005) or even in situ (Ralph et al. 2005) PAM imaging measurements have become commercially available (e.g. the Imaging-PAM systems, Walz, or the FluorCam systems, Photon System Instruments), and the methodology has been applied in a variety of studies on aquatic systems, such as seagrasses (Ralph et al. 2005b), microbial mats (Vopel \& Hawes 2006, Fig. 4), endolithic algae (Grunwald \& Kühl 2004), coral photobiology (Ralph et al. 2005), coral bleaching and disease studies (Hill et al. 2004, Roff et al. 2008). 
Variable chlorophyll fluorescence imaging also helped resolve the distribution and activity of chl $d$-containing phototrophs, identifying a new niche for oxygenic photosynthesis on coral reefs (Kühl et al. 2005). The technique proved ideal to resolve the spatial distribution and activity of both the symbiotic cyanobacteria (Prochloron sp.) living inside ascidians and the underlying biofilm communities harboring the $\mathrm{chl} d$-containing
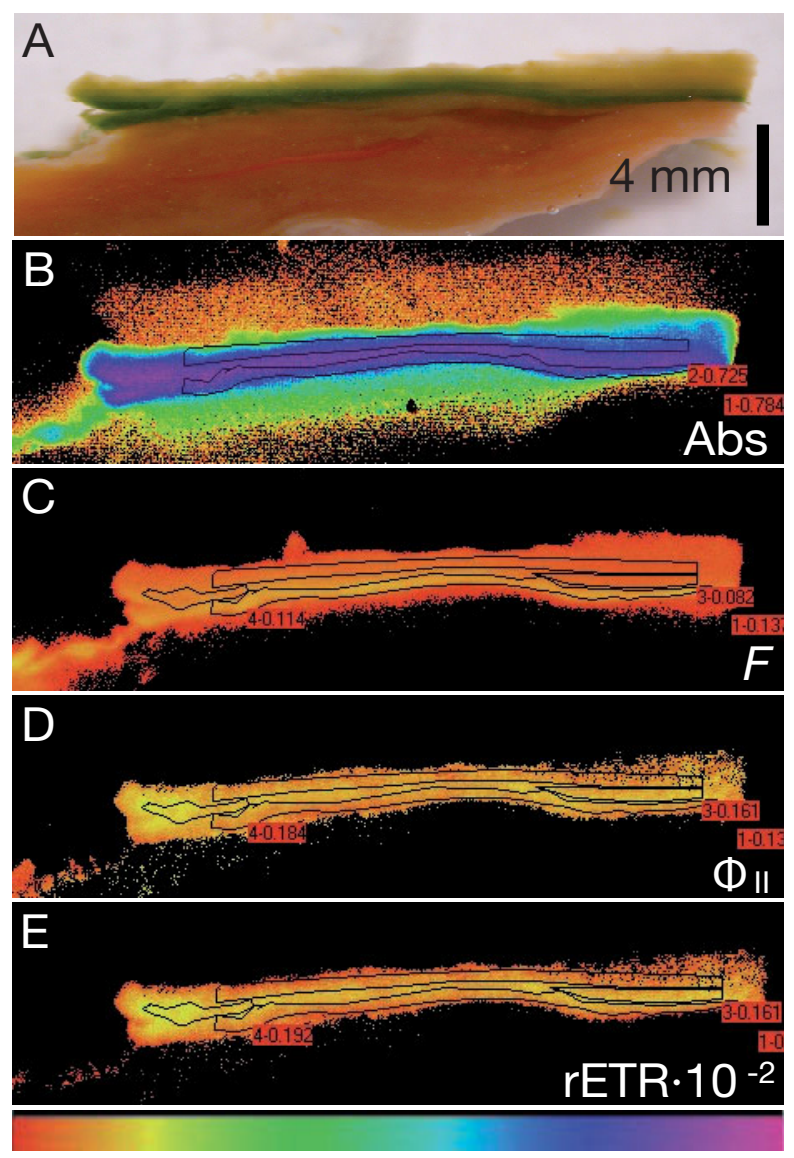

0 1

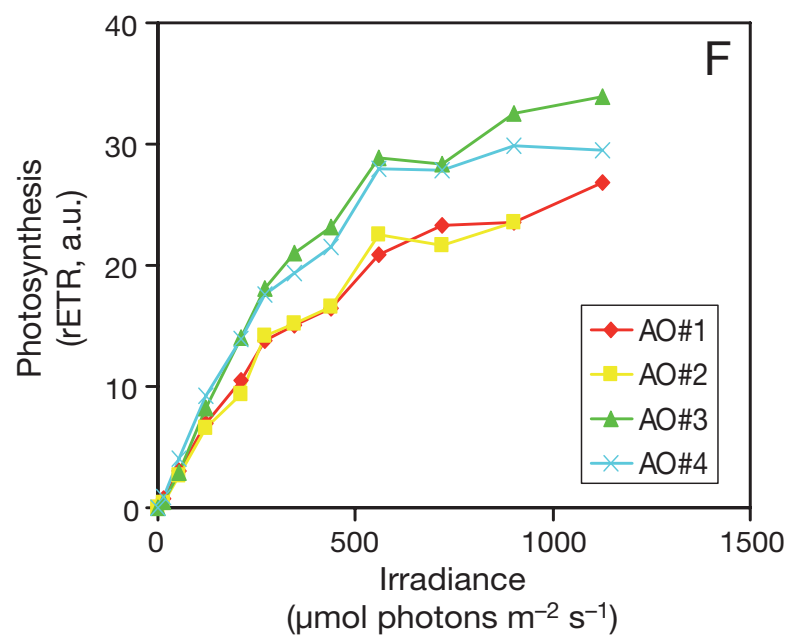

cyanobacterium Acaryochloris marina, which grows under extreme shade in terms of visible wavelengths but, due to its high content of chl $d$, can thrive on far-red wavelengths penetrating through dense overlaying layers of other oxygenic phototrophs (Fig. 5).

Most recently, the use of multicolor red green and blue (RGB) LEDs has enabled microscopic multicolor variable chlorophyll fluorescence imaging (RGB Microscopy PAM, Walz). With such technology, the saturation-pulse technique can be performed with blue $(470 \mathrm{~nm})$, green $(540 \mathrm{~nm})$, red $(650 \mathrm{~nm})$ or white excitation lights, enabling very detailed studies of individual phototrophic cells or even single chloroplasts within algal cells for a wide range of phototrophs in mixed phytoplankton communities. Since the different excitation wavelengths target different functional groups of oxygenic phototrophs (Schreiber et al. 1996, Thar et al. 2001, Schreiber 2005), deconvolution of the chlorophyll fluorescence signals allows separate characterization of these microorganisms in a mixed sample (Fig. 6).

\section{HYPERSPECTRAL IMAGING}

Unlike normal color imaging, where the color information is encoded by a combination of RGB channels, HS imaging assigns multiple spectral channels to each recorded image pixel element (Garini et al. 2006). Since the spectral information reflects the identity of the object, its functional status and/or composition, combining it with spatial information (i.e. size, shape and location of objects), enhances our ability to unravel and understand possible links between the spatial organization and functional relationships amongst different constituents of a studied system. These attributes have made HS imaging instrumental in various areas of basic research and in industrial applications.

Fig. 4. Variable chlorophyll fluorescence imaging of photosynthesis in a hot spring cyanobacterial mat kept under in situ temperature $\left(60\right.$ to $\left.65^{\circ} \mathrm{C}\right)$. (A) The mat was dominated by Synechococcus-like ecotypes in the upper 2 to $3 \mathrm{~mm}$ thick orange/green oxygenic layer on top of a layer dominated by Roseiflexus- and Chloroflexus-type anoxygenic phototrophs (Mushroom Spring, Yellowstone National Park, see Ward et al. 2006). (B-E) Images of the absorptivity of red light (Abs), the chlorophyll fluorescence yield $(F)$, effective quantum yield of PSII, and relative photosynthesis, i.e. rETR, at an irradiance of $\sim 400 \mu \mathrm{mol}$ photons $\mathrm{m}^{-2} \mathrm{~s}^{-1}$. All parameters are scaled to the same dimensionless color bar shown below the panels. (F) Relative ETR (arbitrary units) vs. irradiance in 4 different regions of the microbial mat (AO: area of interest). Data demonstrate how variable chlorophyll fluorescence techniques can enable fast mapping of the spatial distribution of photosynthetic activity, light absorption and acclimatization in microbial mats and other surface-associated communities. M. Kühl (unpubl.) 

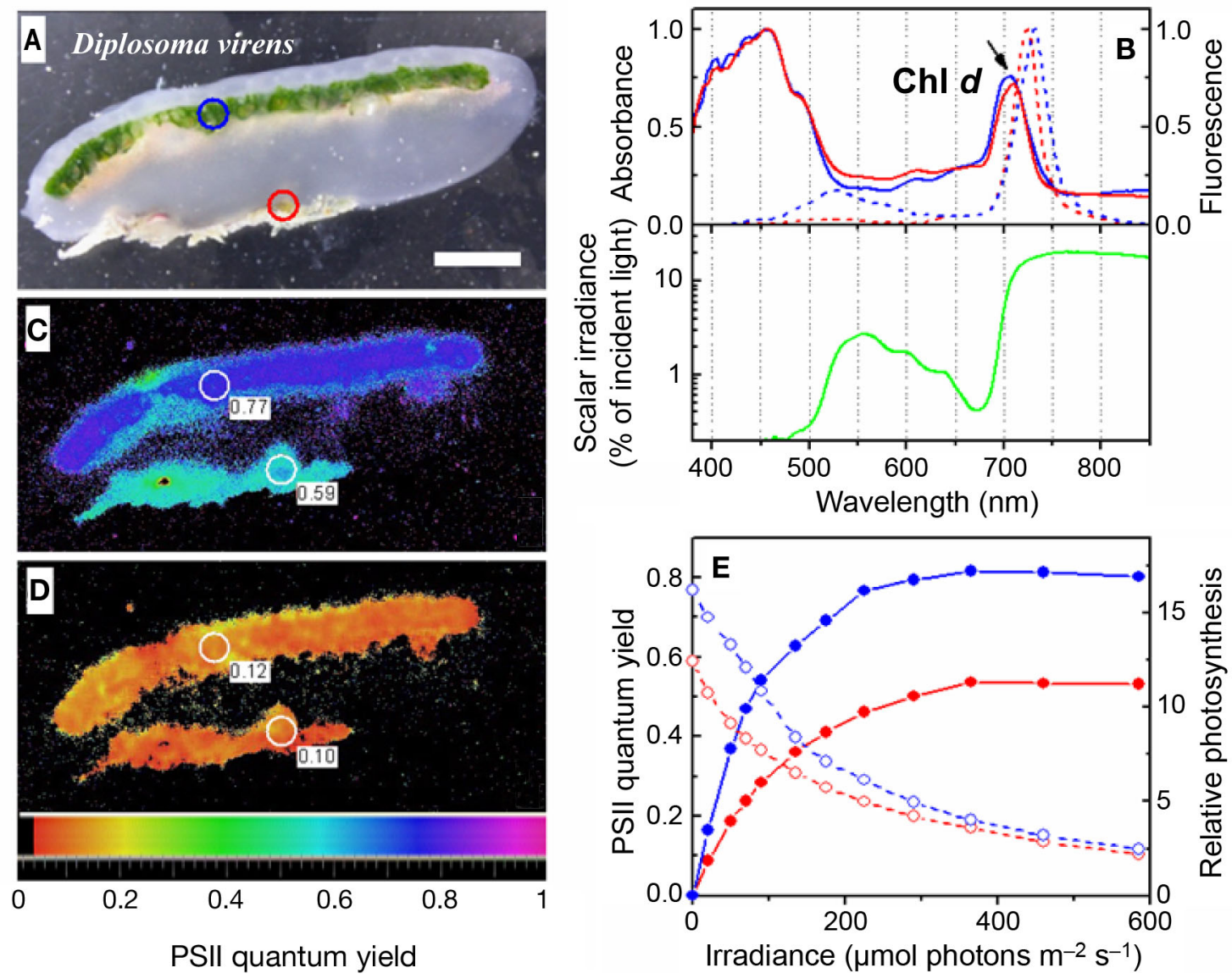

Fig. 5. Variable chlorophyll fluorescence imaging of a cross section of the didemnid ascidian Diplosoma virens. (A) Image showing cyanobacterial symbionts (Prochloron sp.) in its internal cavities (blue ring) and a biofilm on the underside consisting of various phototrophs, including the chl $d$-containing cyanobacterium Acaryochloris marina (red ring). (B) Spectral absorbance (solid lines) and fluorescence (broken lines) of chl $d$ in the biofilm (red curves) and of an $A$. marina culture (blue curves), together with the spectral scalar irradiance reaching the biofilm (green curve). (C, D) Images of (C) maximal PSII quantum yield in the dark adapted state and (D) effective PSII quantum yield under an irradiance of $\sim 600 \mu \mathrm{mol}$ photons $\mathrm{m}^{-2} \mathrm{~s}^{-1}$. (E) Quantum yield (broken lines) and derived rETR rate (solid lines) from the areas of interest shown in panel A as a function of irradiance. These data represent some of the first measurements of $A$. marina photosynthesis in its natural habitat and demonstrate how variable chlorophyll imaging can be used together with other microscale analytical techniques to obtain key information about the microhabitat of specific phototrophs. Reproduced from Kühl et al. (2005)

Early HS systems only allowed for 5 to 10 spectral channels, while state-of-the-art systems now allow several hundred spectral channels per pixel element, enabling acquisition of HS data stacks with excellent spectral resolution from UV to NIR. HS imaging was developed and primarily applied for observations on a large scale, e.g. in astronomy or for air-borne or satellite-based earth remote sensing. In recent years, compact systems have become available for macro- and microscopic applications in the field and laboratory, triggering new applications, e.g. in materials and forensic sciences. Also, HS microscopy is an emerging technology in biomedical research and cell biology (Schultz 2001, Garini et al. 2006), while environmental applications have involved mostly vegetation and mineralogical analyses.
HS imaging in aquatic biology has mainly involved remote sensing at larger spatial scales, ranging from large-scale mapping of plankton in oceans, coastal areas and lakes to, more recently, more local mapping of benthic communities of primary producers in shallow coastal areas and coral reefs (e.g. Hochberg \& Atkinson 2000, Andréfouët et al. 2003a,b, Combe et al. 2005, Deronde et al. 2006). HS imaging has an enormous potential for resolving biomass and distribution of photosynthetic microorganisms in complex microbial communities. However, besides investigations of microphytobenthos distributions at a scale of millimetres to metres on sediments and rock platforms (e.g. Murphy et al. 2004, 2006, Smith et al. 2004, Combe et al. 2005) and some HS fluorescence microscopy studies of corals (e.g. Simon-Blecher et al. 1996, Ainsworth et 

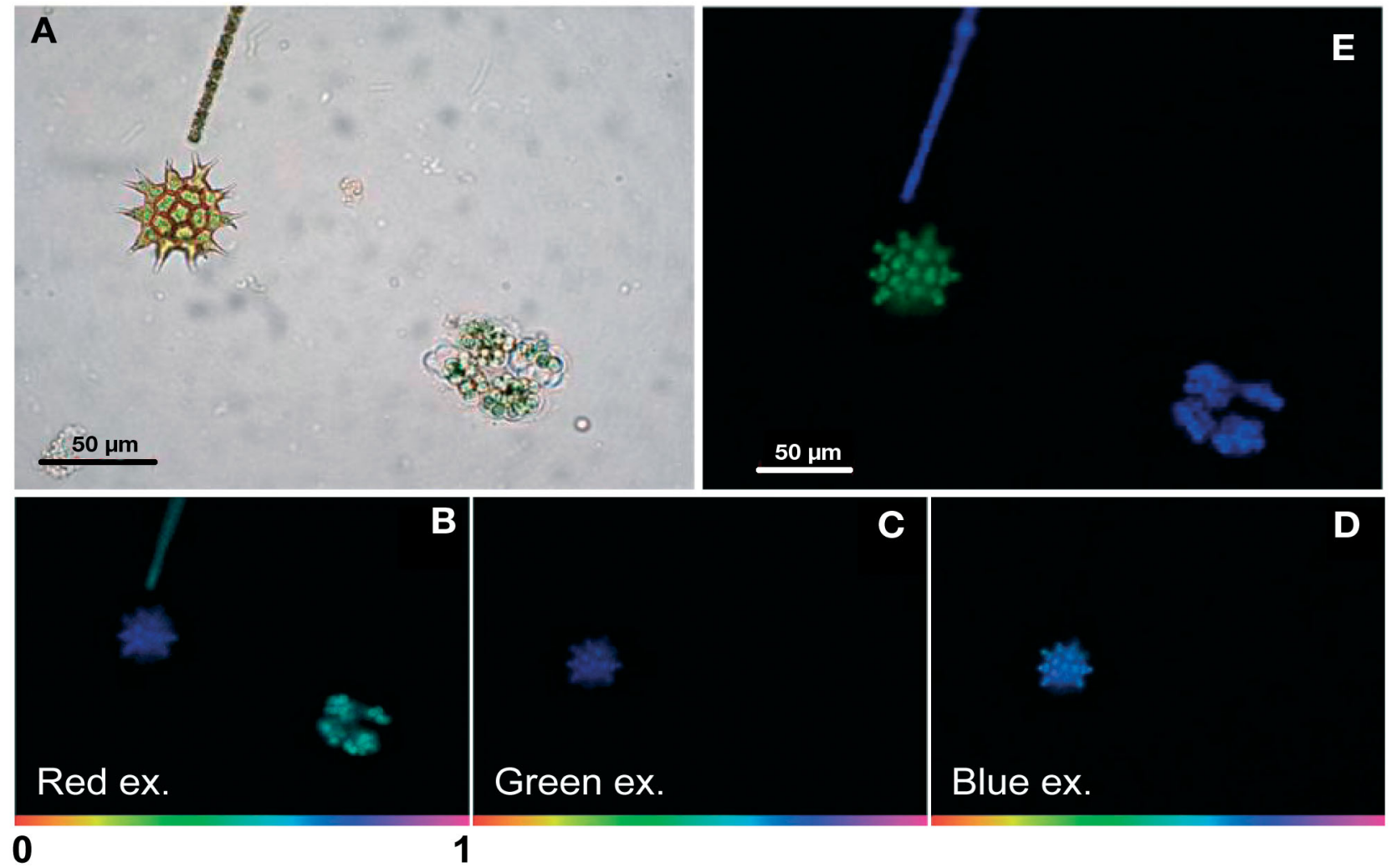

\section{PSII maximum quantum yield}

Fig. 6. Microscopic multicolor variable chlorophyll fluorescence imaging of PSII quantum yield in planktonic phototrophs. (A) Microscope photograph of a sample containing a green alga (Pediastrum sp.), a filamentous cyanobacterium, and an aggregate of unicellular cyanobacteria. (B-D) Images of PS maximum quantum yield obtained with (B) red, (C) green and (D) blue excitation (ex.). (E) Classification of phototrophs (cyanobacteria in blue and green algae in green) according to their variable chlorophyll fluorescence measured by different excitation wavelengths. These data show a first example of how different specific phototrophs and their photosynthetic activity can be analysed and separated in mixed communities (E. Trampe \& M. Kühl unpubl. data)

al. 2006), phototrophic biofilms and single cells (e.g. Neu et al. 2004, Roldán et al. 2004, Larson \& Passy 2005; Vermaas et al. 2008), we are not aware of any micrometre to millimetre scale application of HS imaging in aquatic microbiology beyond our own recent research. The following will thus mainly give a brief introduction to our current HS imaging methodology. The potential of this technology will be demonstrated with a few illustrative samples.

\section{HS imaging systems}

Besides relatively simple 3-chip CCD or complementary metal-oxide-semiconductor (CMOS) cameras that record images in 3 different wavebands (e.g. Murphy et al. 2006), a range of compact, and even portable, true HS imaging systems is commercially available (Garini et al. 2006). Most systems rely on the movement of the investigated sample relative to the HS camera as part of the HS scanning process. One such system has recently been adapted for 2-dimensional mapping of photo-pigment distributions in microbial mats, biofilms and sediments (Polerecky et al. 2007, unpubl., Bachar et al. 2008). The system comprises a laboratory HS camera (Resonon) attached to a motorized stage (VT-80, Micos) mounted onto a heavy stand. While the sample, placed $\sim 5 \mathrm{~cm}$ away from the camera objective, is slowly moved $\left(\sim 80 \mu \mathrm{m} \mathrm{s}^{-1}\right)$ relative to the HS camera, spectral information from a line of 480 pixels (wavelength region 460 to $913 \mathrm{~nm}$, spectral resolution $\sim 2 \mathrm{~nm}$ ) is recorded at $3.75 \mathrm{fps}$. Thus, good quality HS images of a few $\mathrm{mm}^{2}$ to $\mathrm{cm}^{2}$ in size can be acquired with a spatial resolution of $\sim 30 \times 30 \mu \mathrm{m}$ per pixel. By choosing the appropriate illumination, this system allows HS imaging of both the absorption and autofluorescence properties of the pigments in the sample. For the absorption measurement, the sample is illuminated by a broad-band light source, covering the range from visible to near infra-red light (e.g. a halogen lamp or a combination of LEDs). The spectra of the reflected light are recorded and normalized by the 
spectra reflected from the white reference standard (Spectralon, Labsphere), resulting in an HS image of spectral reflectance, $\mathrm{R}(\lambda)$. In contrast, narrow-band light sources, e.g. super-bright LEDs (Lumileds), emitting in blue $(\sim 455 \mathrm{~nm})$, green $(\sim 530 \mathrm{~nm})$ or amber ( 590 nm), and equipped with a short-pass filter, are used to excite pigment autofluorescence. The HS images of autofluorescence, $F(\lambda)$, are then recorded through a complementary long-pass optical filter (Bachar et al. 2008, L. Polerecky et al. unpubl.).

Other HS imaging systems use a special linescanning device inserted between the objective and the CCD chip of the HS camera. Such systems do not rely on moving the sample relative to the camera objective during the HS scan, and can thus be much more easily adapted to standard optical microscopes. One such system (VNIR-100E, Emerging Technologies) has recently been adapted for investigating the distribution and abundance of different types of photosynthetic microorganisms in a phototrophic biofilm growing below an ascidian (M. Kühl et al. unpubl.). With this system, HS images of spectral reflectance can be acquired through a dissection scope or directly via a macro-objective. Alternatively, the HS camera can be mounted onto a compound microscope operating in a transmission mode, providing the opportunity to acquire high quality HS images with a single-cell resolution. In both configurations, the illumination by a broad-band light source (e.g. a halogen or xenon lamp), used for the HS imaging of absorption properties of the sample, can easily be exchanged with the appropriate combination of an excitation light source (e.g. super-bright LEDs) with excitation/emission band-pass filters, providing the opportunity to acquire HS images of autofluorescence with a similarly high spatial resolution.

Besides the systems mentioned above, which can also readily be used for field studies, advanced confocal laser scanning microscopes with a flexible excitation range and multiple spectral detection channels (e.g. Leica SP5 or similar microscopes) have aided a number of laboratory studies investigating the complex 3-dimensional structure of cells in natural phototrophic biofilms (Roldán et al. 2004, Larson \& Passy 2005) and in coral-associated bacterial communities (Ainsworth et al. 2006). Such systems are under rapid development and, most recently, even sub-cellular pigment distributions within small unicellular cyanobacteria have been resolved (Vermaas et al. 2008).

\section{Identification of pigments from HS data}

There is a large body of literature on the interpretation and analysis of HS datasets (e.g. Harris 2006), and specialized software packages, such as ENVI (ITT Visual Information Solutions), are commercially available for advanced analysis. However, a detailed discussion of HS data analysis is beyond the scope of this paper, and we just present one example of a relatively simple analytical approach.

Our HS datasets were analyzed using the available in vivo absorption and fluorescence characteristics of the targeted pigments. Specifically, the 4 th derivative of the reflectance spectrum in the wavelength corresponding to the absorption maximum of a given pigment $\left(\lambda_{1}\right)$ was taken as a relative measure of the local pigment concentration $(p): p_{1} \sim \mathrm{d}^{4} \mathrm{R}\left(\lambda_{1}\right) / \mathrm{d} \lambda^{4}$ (Bachar et al. 2008, L. Polerecky et al. unpubl.). This approach is commonly used in spectroscopy (Butler \& Hopkins 1970, Fleissner et al. 1996) to identify wavelengths of absorption maxima in spectra with a multitude of possibly overlapping absorption peaks. The approach is based on the rationale that higher abundance of a pigment absorbing maximally at $\lambda_{1}$ results in a more pronounced trough in the transmission or reflectance spectrum, $R(\lambda)$, at this wavelength. Mathematically, a deeper trough in $R(\lambda)$ at $\lambda_{1}$ is characterized by more pronounced 2nd (curvature) and 4 th derivatives of the function $R(\lambda)$ in $\lambda_{1}$. Because the 2nd derivative is more sensitive to the presence of another absorption peak centered at a close-by wavelength, $\lambda_{2}$, the 4 th derivative is a more robust parameter for quantification of the pigment with maximum absorption at $\lambda_{1}$ (Butler \& Hopkins 1970, Fleissner et al. 1996, L. Polerecky et al. unpubl.). The autofluorescence HS images were analyzed by fitting the fluorescence spectrum in each pixel with a linear combination of Lorenzian and/or Gaussian peak functions, centered at specific wavelengths corresponding to in vivo emission maxima of the targeted pigments. The magnitudes of the peaks were then taken as relative measures for the local concentrations of the corresponding pigments (L. Polerecky et al. unpubl.). In both analyses, the calculated relative concentrations of the targeted pigments were colorcoded and displayed as R, G and B channels in composite RGB images. The software that enables this simple analysis is freely available from the authors.

\section{Identification and spatial discrimination of pigments in mixed microbial communities}

HS imaging methodology allows very sensitive and minimally invasive identification, localization and relative quantification of pigments in microbial samples. The pigments can be identified based on their absorption and/or autofluorescence properties. Pigment analysis is fast, sensitive, and can be done on freshly collected samples without the need for sample process- 

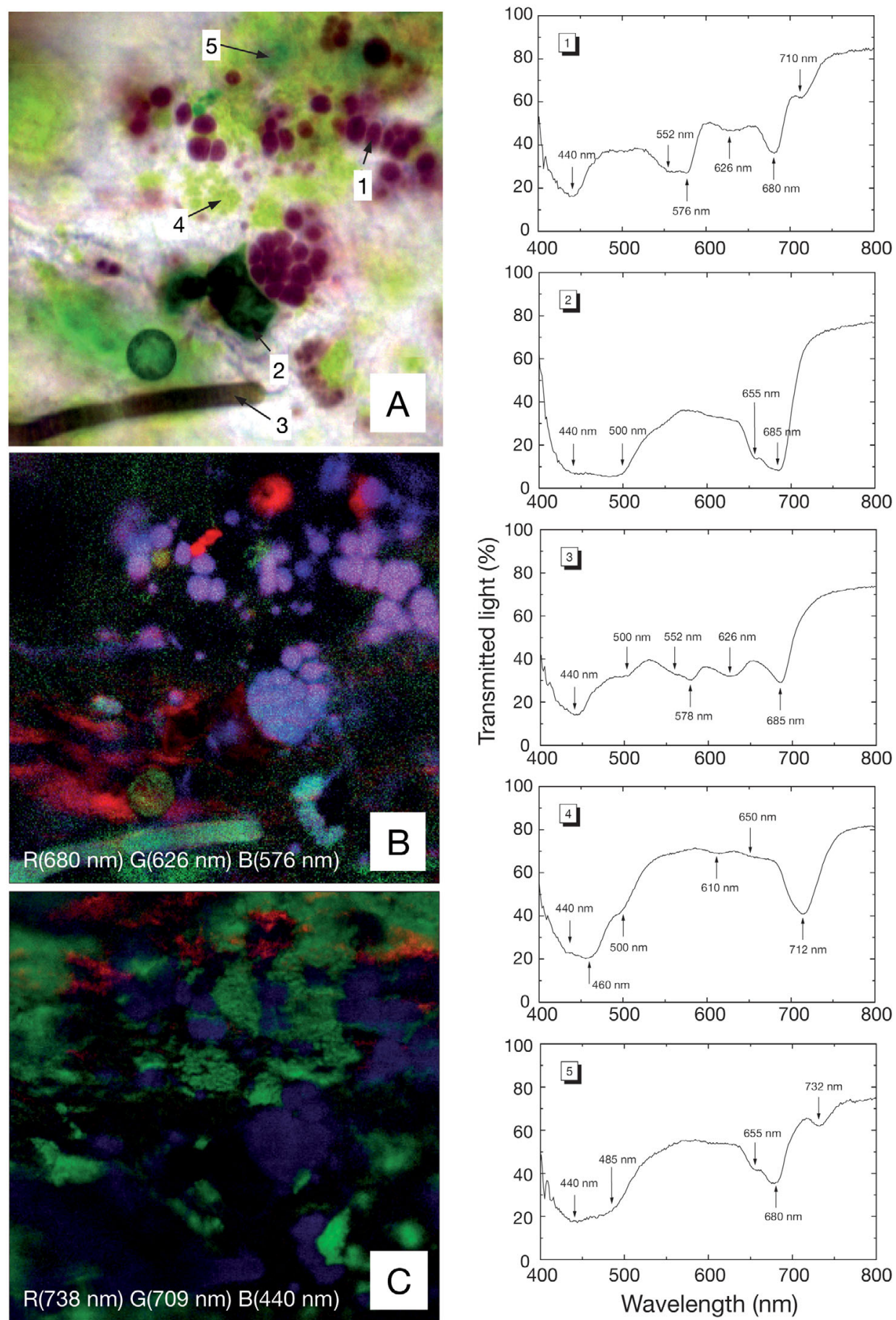

Fig. 7. Microscopic hyperspectral imaging of a phototrophic biofilm growing on the underside of a didemnid ascidian (see Fig. 5). (A) Direct image of the cells in the biofilm, as they would approximately appear to the naked eye under white illumination. Numbers in the image show specific morphotypes for which transmission spectra are shown in the panels to the right: red algae (1), green algae (2), cyanobacterial filament (3), small cyanobacteria with chl $d$ (4), mixed green algae and cyanobacteria (5). Distinct spectral minima indicate the presence of chl a (440 and $680 \mathrm{~nm})$, chl $b(650-655 \mathrm{~nm})$, chl $d(710-712 \mathrm{~nm})$, phycoerythrin $(576 \mathrm{~nm})$, phycocyanin $(626 \mathrm{~nm})$ and a near infra-red absorbing pigment (732 nm, which could be due to a specialized chlorophyll antenna of the green alga Ostreobium sp. or due to presence of Bchl $c$-containing phototrophs). (B,C) Composite images of the 4 th derivative of the transmission spectrum in wavelengths corresponding to the absorption maxima of selected pigments (see details in respective panels), indicating the distribution and relative abundance of the different pigments and their association with different phototrophic morphotypes in the sample, e.g. green in panel C indicates the chl $d$-containing cyanobacterium Acaryochloris marina (M. Kühl et al. unpubl. data) 
ing. The measuring systems are portable and relatively low-cost, thus suitable for field measurements.

Combination of the HS camera with a microscope allows identification of pigments in single cells (Fig. 7). This identification can, for example, be done by comparison of the in vivo transmission spectra, averaged over each cell, with the absorption spectra of known pigments. Furthermore, using the 4th derivative approach as implemented in our analytical software, the relative concentration of any targeted pigment can be automatically quantified and visualized as a pigment distribution image. By overlying the pigment images with the outline of the cells seen by direct microscopy, the cells can be identified (e.g. assigned to a specific functional group) or classified based on their pigment content.

Macroscopic HS imaging allows semi-quantitative visualization of pigments in mixed phototrophic communities (Fig. 8). The imaging technique has a high resolution which captures the dramatic spatial varia-
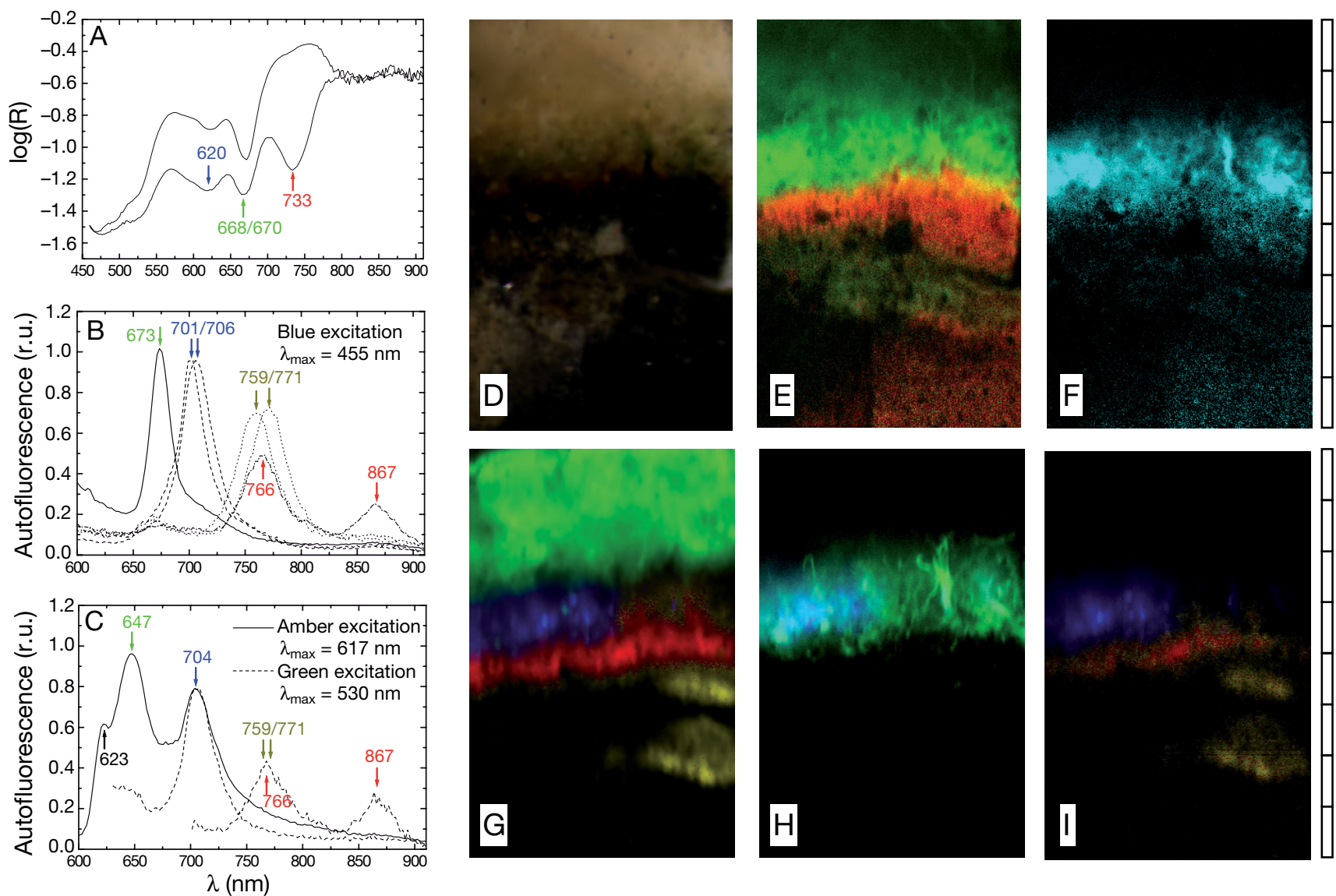

Fig. 8. Macroscopic hyperspectral imaging of reflectance and autofluorescence in a vertical section of a microbial mat. (A) Logtransformed reflectance spectra, $\log R(\lambda)$. (B-C) Autofluorescence (relative units) spectra emitted from the mat upon excitation by (B) blue, and (C) amber and green LEDs. Different line-types in panels B and C correspond to different points in the mat and different excitation lights, respectively. Arrows in panels A-C indicate wavelengths of the pigment-specific spectral features. (D) Direct image of the mat, as it would approximately appear to the naked eye under white illumination. (E-I) Spatial distributions of pigments characterized by the spectral features depicted in panels A-C. Red and green colors in panel E correspond to the 4th derivative of the reflectance spectra at $733 \mathrm{~nm}(\mathrm{Bchl} c)$ and 668/670 $\mathrm{nm}(\mathrm{chl}$ a), respectively, while cyan in panel F corresponds to the 4th derivative at $620 \mathrm{~nm}$ (phycocyanin) (shown in A). Red, green, blue and dark yellow colors in panel G correspond to the magnitudes of auto-fluorescence peaks excited by blue light and emitted at 766 and $867 \mathrm{~nm}(\mathrm{Bchl} c$ and Bchl a), 673 and $701 / 706$ $\mathrm{nm}(\mathrm{chl} \mathrm{a})$ and $759 / 771 \mathrm{~nm}(\mathrm{Bchl}$ ), respectively (shown in B). Green and blue colors in panel H correspond to the magnitudes of auto-fluorescence peaks excited by amber light and emitted at $647 \mathrm{~nm}$ (phycobiliproteins) and $704 \mathrm{~nm}$ (chl a), respectively (shown by solid line in C). Red, blue and dark yellow colors in (I) correspond to the magnitudes of autofluorescence peaks excited by green light and emitted at $766+867 \mathrm{~nm}($ Bchl $a$ and $c), 704 \mathrm{~nm}(\mathrm{chl} a)$ and 759/771 nm (Bchl c), respectively (shown by dashed lines in C). Vertical scale in $\mathrm{mm}$ is shown to the right. Images show pronounced stratification of the different functional groups of phototrophic microorganisms in the mat on a mm scale, inferred from the spatial distribution of the pigments associated with each group. The layer dominated by cyanobacteria (cyan and green in F and H, blue in $\mathrm{G}$ and I) appears to be sandwiched between the layers dominated by diatoms from the top (green in E and G) and anoxygenic photosynthetic bacteria from the bottom (red in E, G and I), although overlapping regions where the populations co-exist do seem to be also present (L. Polerecky unpubl. data) 
tion of physico-chemical parameters (e.g. light quantity and quality, $\mathrm{pH}$, concentrations of $\mathrm{O}_{2}$ and $\mathrm{H}_{2} \mathrm{~S}$ ) that characterize the microenvironments of the studied microbial communities. This makes macroscopic HS imaging a powerful tool for the study of the role spatial organization of microorganisms plays in the ecological functioning of complex microbial communities, or to non-invasively monitor changes in the spatial organization and/or composition of a microbial community in response to changing environmental factors.

\section{EMERGING TECHNIQUES FOR FUNCTIONAL IMAGING IN MICROBIAL ECOLOGY}

Besides the methods described above, two other imaging techniques are increasingly applied for functional imaging in aquatic microbiology. NMR spectroscopy, especially pulsed field gradient-NMR, is a powerful non-invasive method for investigating the structure and mass-transfer properties of environmental samples (e.g. Beuling et al. 1998). While NMR imaging is frequently applied in plant, animal and medical sciences, applications in microbiology are still scarce. NMR imaging studies in environmental micro- biology have been conducted on microbial mats (Wieland et al. 2001), biofilms (e.g. Manz et al. 2003, Majors et al. 2005) and sponges (Bringmann et al. 1999). Application of NMR microscopy for the analysis of single cells and aggregates of microorganisms is a fascinating new method that has just been introduced to microbiology (McLean et al. 2008). Combined with confocal laser microscopy, NMR can visualize and overlay biofilm structure with the spatial distribution of metabolic compounds and hence bacterial activity. NMR imaging techniques involve the use of expensive and complicated equipment and data analysis, which is mainly available in dedicated research centers such as the large-scale NMR facilities of the European Union, where good technical expertise is available for users.

Another high-tech imaging technique with an enormous potential for functional imaging of aquatic microorganisms is multi-isotope imaging mass spectrometry (MIMS). After incubation of an environmental sample with various radioactive- or stable isotopelabeled substrates, the distribution of the incorporated labels can be imaged at single-cell resolution. The spatial resolution can be further increased with a NANOsecondary ion mass spectrometer (NANO-SIMS)
A

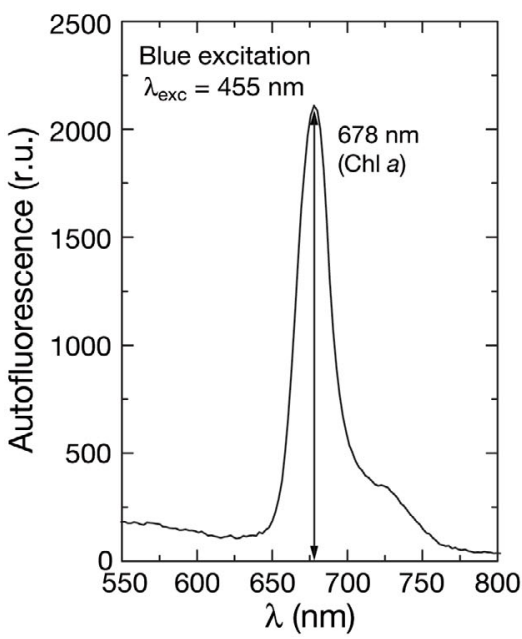

B

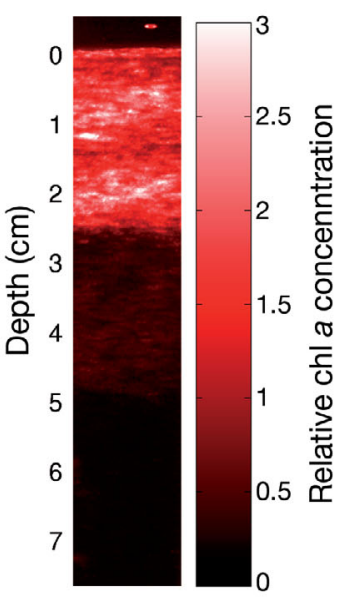

C

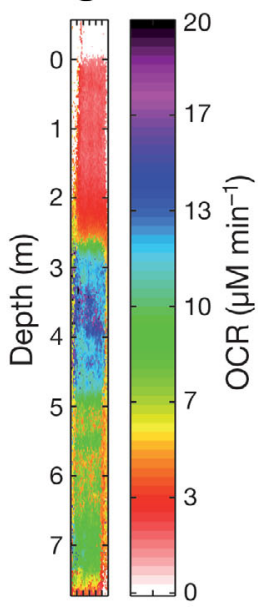

D

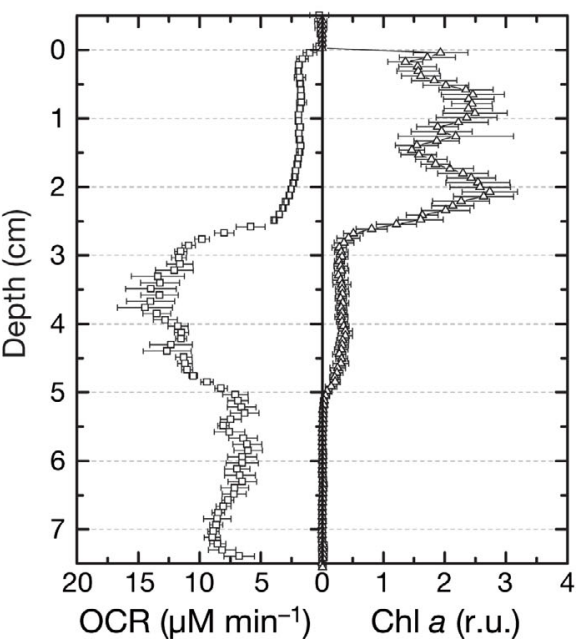

Fig. 9. Combined mapping of pigment distribution and $\mathrm{O}_{2}$ consumption activity in permeable intertidal coastal sediment. (A) Spectrum of autofluorescence emitted by chl a containing diatoms found in the sediment. (B) Image of relative chl a concentration in the sediment, as calculated from the magnitude of the chl a autofluorescence peak measured by hyperspectral imaging. (C) Image of potential $\mathrm{O}_{2}$ consumption rates (OCR) in the same sediment sample as in panel B, determined by the flow-through method of Polerecky et al. (2005) using planar $\mathrm{O}_{2}$ optodes. (D) Depth profiles of the relative chl a concentration and OCR in the same core, as calculated by horizontally averaging the respective images shown in panels B and C. Error bars represent standard deviation of the horizontal averages, r.u. = relative units. The data show a clear separation of the surface sediment into 3 zones, each characterized by distinct average respiration activity and pigment content, and suggest a possible link between the pigment content and the prevalent biogeochemical processes occurring in the sediment. While the diatom cells found in the top $2.5 \mathrm{~cm}$ may be responsible for the observed respiration, lower chl a content in the 2.5 to $5 \mathrm{~cm}$ layer may indicate dead or partially degraded cells that serve as a fresh organic carbon (C-org) source for anaerobic degradation, which manifests itself through elevated oxygen consumption rates due to the accumulation of reduced compounds. The layer below $5 \mathrm{~cm}$, which is devoid of chl a and characterized by intermediate OCR, may correspond to a region with different quality of C-org for degradation and reactivity of the accumulated reduced compounds towards oxygen (Polerecky et al. 2005, L. Polerecky et al. unpubl.) 
(Lechene et al. 2006). This technique has already yielded fascinating new insights into aspects of microbial physiology, e.g. the regulation of cyanobacterial $\mathrm{N}_{2}$ fixation (Lechene et al. 2007, Popa et al. 2007). Most recently, this technique has been combined with oligonucleotide hybridization techniques for simultaneous identification and functional studies of bacteria, enabling in situ ecophysiology of uncultured microorganisms within complex microbial communities (Li et al. 2008).

\section{CONCLUSIONS}

Rapid development in photonics and optoelectronics have made advanced imaging techniques available in aquatic environmental microbiology, providing the opportunity to image microbial activity, microbial identity and physico-chemical microenvironments in natural microbial communities at high spatio-temporal resolution. Thus, detailed structural analysis using advanced confocal and HS imaging methods can now be linked to the detailed mapping of function at scales ranging from the subcellular and single-cell levels to entire communities. In this paper, we have given a short overview of 3 types of functional imaging techniques that represent powerful tools for aquatic microbial ecology and which are starting to become more widespread.

The next important step is to combine several different imaging techniques on the same sample/system. We are currently realizing such studies by, for example, combining $\mathrm{HS}, \mathrm{O}_{2}$ and variable chlorophyll fluorescence imaging. An example of this approach is shown in Fig. 9, where HS imaging of chlorophyll (chl a) distribution in permeable coastal sediment was combined with imaging of the $\mathrm{O}_{2}$ consumption derived from planar $\mathrm{O}_{2}$ optode measurements.

Although great progress has been made in the development of new imaging techniques, not all functional parameters relevant for aquatic microbial ecology can currently be imaged. Combination of the imaging techniques discussed in this paper with other high spatial resolution techniques, such as microsensor measurements, is a promising approach for gaining new insights into the microenvironmental controls of structure and function in aquatic microbial communities.

Acknowledgements. Our research on functional imaging is funded by the Danish Research Council for Technology and Production, the Danish National Advanced Technology Foundation, the Danish Natural Science Research Council, the Carlsberg Foundation (M.K.); the European Aeronautic Defence and Space Company (EADS), the European Commission and the Max-Planck-Society (L.P.). We acknowledge colleagues, technicians and students for contributing to and co-authoring past and present work on functional imaging, and for essential technological developments. We especially thank R. Glud, R. Thar, L. F. Rickelt, I. Klimant, G. Mistlberger, S. Borisov, G. Holst, B. Grunwald, M. Staal, A. Wieland, U. Schreiber, T. Larkum, P. Ralph, E. Trampe, C. Schröder, U. Franke, M. Al Najjar, J. Fischer, P. Faerber, H. Osmers, G. Herz, A. Kutsche, N. Volkenborn, P. Stief, A. Bissett, P. Suci, P. Stoodley, H. Jonkers and D. de Beer.

\section{LITERATURE CITED}

Ainsworth TD, Fine M, Blackall L, Hoegh-Guldberg O (2006) Fluorescence in situ hybridization and spectral imaging of coral-associated bacterial communities. Appl Environ Microbiol 72:3016-3020

Andréfouët S, Payri C, Hochberg EJ, Che LM, Atkinson MJ (2003a) Airborne hyperspectral detection of microbial mat pigmentation in Rangiroa atoll (French Polynesia). Limnol Oceanogr 48:426-430

Andréfouët S, Hochberg EJ, Payri C, Atkinson MJ, MullerKarger FE, Ripley H (2003b) Multi-scale remote sensing of microbial mats in an atoll environment. Int J Remote Sens 24:2661-2682

Bachar A, Polerecky L, Fischer J, Vamvakopoulos K, de Beer D, Jonkers H (2008) Two-dimensional mapping of photopigments distribution and activity of Chloroflexus-like bacteria in a hypersaline microbial mat. FEMS Microbiol Ecol 65:434-448

Baker NR (2008) Chlorophyll fluorescence: A probe of photosynthesis in vivo. Annu Rev Plant Biol 59:89-113

Beuling EE, van Dusschoten D, Lens P, van den Heuvel JC, van As H, Ottengraf SPP (1998) Characterization of the diffusive properties of biofilms using pulsed field gradient-nuclear magnetic resonance. Biotechnol Bioeng 60:283-291

Billerbeck M, Werner U, Polerecky L, Walpersdorf E, de Beer D, Huettel M (2006) Surficial and deep pore water circulation governs spatial and temporal scales of nutrient recycling in intertidal sand flat sediment. Mar Ecol Prog Ser 326:61-76

Borisov SM, Klimant I (2007) Ultrabright oxygen optodes based on cyclometalated iridium(III) coumarin complexes. Anal Chem 79:7501-7509

> Borisov S, Krause C, Arain S, Wolfbeis OS (2006a) Composite material for simultaneous and contactless sensing and imaging of oxygen and carbon dioxide. Adv Math 18:1511-1516

Borisov SM, Vasylevska AS, Krause C, Wolfbeis OS (2006b) Composite luminescent material for dual sensing of oxygen and temperature. Adv Funct Mater 16:1536-1542

Bringmann G, Wolf K, Lanz T, Haase A, Hiort J, Proksch P, Müller WEG (1999) Direct demonstration of spatial water distribution in the sponge Suberites domuncula by in vivo NMR imaging. Mar Ecol Prog Ser 189:307-310

$>$ Butler WL, Hopkins DW (1970) Analysis of fourth derivative spectra. Photochem Photobiol 12:451-456

> Combe JP, Launeau P, Carrere V, Despan D, Meleder V, Barille L, Sotin C (2005) Mapping microphytobenthos biomass by non-linear inversion of visible-infrared hyperspectral images. Remote Sens Environ 98:371-387

Davison W, Fones GR, Harper M, Teasdale P, Zhang H (2000) Dialysis, DET and DGT: In situ diffusional techniques for studying water, sediments and soils. In: Buffle J, Horvai G (eds), In situ monitoring of aquatic systems: chemical analysis and speciation. Wiley, Chichester, p 495-569 
Deronde B, Kempeneers P, Forster RM (2006) Imaging spectroscopy as a tool to study sediment characteristics on a tidal sandbank in the Westerschelde. Estuar Coast Shelf Sci 69:580-590

Falkowski PG, Koblíïek M, Gorbunov M, Kolber Z (2005) Development and application of fluorescence techniques in marine ecosystems. In: Papageorgiou GC, Govindjee (eds), Chlorophyll fluorescence: a signature of photosynthesis. Advances in photosynthesis and respiration series 19. Kluwer Academic Publishers, Dordrecht, p 757-778

Fleissner G, Hage W, Hallbrucker A, Mayer E (1996) Improved curve resolution of highly overlapping bands by comparison of 4 th-derivative curves. Appl Spectrosc 50:1235-1245

Franke U, Polerecky L, Precht E, Huettel M (2006) Wave tank study of particulate organic matter degradation in permeable sediments. Limnol Oceanogr 51:1084-1096

Frederiksen MS, Glud RN (2006) Oxygen dynamics in the rhizosphere of Zostera marina: a 2-dimensional planar optode study. Limnol Oceanogr 51:1072-1083

- Garini Y, Young IT, McNamara G (2006) Spectral imaging: principles and applications. Cytometry A 69:735-747

> Glud RN, Ramsing NB, Gundersen JK, Klimant I (1996) Planar optrodes: a new tool for fine scale measurements of twodimensional $\mathrm{O}_{2}$ distribution in benthic communities. Mar Ecol Prog Ser 140:217-226

Glud RN, Kühl M, Kohls O, Ramsing NB (1999) Heterogeneity of oxygen production and consumption in a photosynthetic microbial mat as studied by planar optodes. J Phycol 35:270-279

Glud RN, Tengberg A, Kühl M, Hall P, Klimant I, Holst G (2001) An in situ instrument for planar $\mathrm{O}_{2}$ optode measurements at benthic interfaces. Limnol Oceanogr 46: 2073-2080

Glud RN, Wenzhöfer F, Tengberg A, Middelboe M, Oguri K, Kitazato H (2005) Distribution of oxygen in surface sediments from central Sagami Bay, Japan: In situ measurements by microelectrodes and planar optodes. Deep Sea Res Part I Oceanogr Res Pap 52:1974-1987

Grunwald B, Kühl M (2004) A system for imaging variable chlorophyll fluorescence of aquatic phototrophs. Ophelia 58:79-89

Harris AT (2006) Spectral mapping tools from the earth sciences applied to spectral microscopy data. Cytometry A 69:872-879

Hill R, Schreiber U, Gademann R, Larkum AWD, Kühl M, Ralph P (2004) Spatial heterogeneity of photosynthesis and the effect of temperature-induced bleaching conditions in 3 species of corals. Mar Biol 144:633-640

Hochberg EJ, Atkinson MJ (2000) Spectral discrimination of coral reef benthic communities. Coral Reefs 19:164-171

> Holst G, Grunwald B (2001) Luminescence lifetime imaging with transparent oxygen optodes. Sens Act B 74:78-90

Holst G, Kohls O, Klimant I, König B, Richter T, Kühl M (1998) A modular luminescence lifetime imaging system for mapping oxygen distribution in biological samples. Sens Act B 51:163-170

Holst G, Grunwald B, Klimant I, Kühl M (1999) A luminescence lifetime imaging system using imaging fibers to measure the 2D distribution of $\mathrm{O}_{2}$ in biological samples. SPIE Proc 3860:154-163

Holst G, Klimant I, Kohls O, Kühl M (2000) Optical microsensors and microprobes. In: Varney MS (ed), Chemical sensors in oceanography, Gordon \& Breach, Amsterdam, p 143-188

- Huber C, Klimant I, Krause C, Werner T, Mayr T, Wolfbeis OS (2000) Optical sensor for seawater salinity. Fresenius J
Anal Chem 368:196-202

Jensen SI, Kühl M, Glud RN, Jørgensen LB, Priemé A (2005) Oxic microzones and radial oxygen loss from roots of Zostera marina. Mar Ecol Prog Ser 293:49-58

Jørgensen BB, Des Marais DJ (1990) The diffusive boundary layer of sediments: oxygen microgradients over a microbial mat. Limnol Oceanogr 35:1343-1355

Klimant I (1997) Ger. Pat. Appl., DE 198.29.657

> Klimant I, Kühl M, Glud RN, Holst G (1997) Optical measurement of oxygen and temperature in microscale: strategies and biological applications. Sens Act B 38:29-37

König B, Kohl O, Holst G, Glud RN, Kühl M (2005) Fabrication and test of sol-gel based planar oxygen optodes for use in aquatic sediments. Mar Chem 97:262-276

Kromkamp JC, Forster RM (2003) The use of variable fluorescence measurements in aquatic ecosystems: differences between multiple and single turnover measuring protocols and suggested terminology. Eur J Phycol 38:103-112

Kühl M (2005) Optical microsensors for analysis of microbial communities. Methods Enzymol 397:166-199

Kühl M, Revsbech NP (2001) Biogeochemical microsensors for boundary layer studies. In: Boudreau BP, Jørgensen BB (eds), The benthic boundary layer. Oxford University Press, Oxford, p 180-210

Kühl M, Lassen C, Revsbech NP (1997) A simple light meter for measurements of PAR (400 to $700 \mathrm{~nm}$ ) with fiber-optic microprobes: application for $P$ vs. $E_{0}$ (PAR) measurements in a microbial mat. Aquat Microb Ecol 13: 197-207

Kühl M, Chen M, Ralph PJ, Schreiber U, Larkum AWD (2005) A niche for cyanobacteria containing chlorophyll $d$. Nature 433:820

Kühl M, Rickelt LF, Thar R (2007) Combined imaging of bacteria and oxygen in biofilms. Appl Environ Microbiol 73:6289-6295

Kühl M, Holst G, Larkum AWD, Ralph PJ (2008) Imaging of oxygen dynamics within the endolithic algal community of the massive coral Porites lobata (Dana). J Phycol 44: $541-550$

> Larson C, Passy SI (2005) Spectral fingerprinting of algal communities: a novel approach to biofilm analysis and biomonitoring. J Phycol 41:439-446

Lechene C, Hillion F, McMahon G, Benson D and others (2006) High-resolution quantitative imaging of mammalian and bacterial cells using stable isotope mass spectrometry. J Biol 5:20

Lechene CP, Luyten Y, McMahon G, Distel D (2007) Quantitative imaging of nitrogen fixation by individual bacteria within animal cells. Science 317:1563-1566

Li T, Wu TD, Mazéas L, Toffin L, Guerquin-Kern JL, Leblon G, Bouchez T (2008) Simultaneous analysis of microbial identity and function using NanoSIMS. Environ Microbiol 10:580-588

- Liebsch G, Klimant I, Frank B, Holst G, Wolfbeis OS (2000) Luminescence lifetime imaging of oxygen, $\mathrm{pH}$, and carbon dioxide distribution using optical sensors. Appl Spectrosc 54:548-559

> Majors PD, McLean JS, Pinchuk GE, Fredrickson JK, Gorby YA, Minard KR, Wind RA (2005) NMR methods for in situ biofilm metabolism studies. J Microbiol Methods 62: $337-344$

> Manz B, Volke F, Goll D, Horn H (2003) Measuring local flow velocities and biofilm structure in biofilm systems with magnetic resonance imaging (MRI). Biotechnol Bioeng 84: 424-432

> McLean JS, Ona ON, Majors PD (2008) Correlated biofilm imaging, transport and metabolism measurements via combined nuclear magnetic resonance and confocal 
microscopy. ISME J 2:121-131

Murphy RJ, Tolhurst TJ, Chapman MG, Underwood AJ (2004) Estimation of surface chlorophyll on an exposed mudflat using digital color infrared (CIR) photography. Estuar Coast Shelf Sci 59:625-638

Murphy RJ, Underwood AJ, Pinkerton MH (2006) Quantitative imaging to measure photosynthetic biomass on an intertidal rock-platform. Mar Ecol Prog Ser 312:45-55

Nagl S, Wolfbeis OS (2007) Optical multiple chemical sensing: status and current challenges. Analyst (Lond) 132: 507-511

Nedbal L, Whitmarsh J (2005) Chlorophyll fluorescence imaging of leaves. In: Papageorgiou GC, Govindjee (eds) Chlorophyll fluorescence: a signature of photosynthesis. Advances in photosynthesis and respiration series 19. Kluwer Academic Publishers, Dordrecht, p 389-407

Neu TR, Woelfl S, Lawrence JR (2004) Three-dimensional differentiation of photo-autotrophic biofilm constituents by multi-channel laser scanning microscopy (single-photon and 2-photon excitation). J Microbiol Methods 56:161-172

O'Donovan C, Hynes J, Yashunki D, Papkovsky DB (2005) Phosphorescent oxygen-sensitive materials for biological applications. J Mater Chem 15:2946-2951

Oguri K, Kitazato H, Glud RN (2006) Platinum octaetylporphyrin based planar optodes combined with an UV-LED excitation light source: an ideal tool for high-resolution $\mathrm{O}_{2}$ imaging in $\mathrm{O}_{2}$ depleted environments. Mar Chem 100: 95-107

Oxborough K (2004) Imaging of chlorophyll a fluorescence: theoretical and practical aspects of an emerging technique for the monitoring of photosynthetic performance. J Exp Bot 55:1195-1205

Oxborough K (2005) Using chlorophyll a fluorescence imaging to monitor photosynthetic performance. In: Papageorgiou G, Govindjee (eds), Chlorophyll fluorescence: a signature of photosynthesis. Advances in photosynthesis and respiration series 19. Kluwer Academic Publishers, Dordrecht, p 409-428

Oxborough K, Hanlon ARM, Underwood GJC, Baker NR (2000) In vivo estimation of the photosystem II photochemical efficiency of individual microphytobenthos cells using high-resolution imaging of chlorophyll a fluorescence. Limnol Oceanogr 45:1420-1425

Papageorgiou G, Govindjee (2005) Chlorophyll fluorescence: a signature of photosynthesis. Advances in photosynthesis and respiration series 19. Kluwer Academic Publishers, Dordrecht

Papkovsky DB (2004) Methods in optical oxygen sensing: protocols and critical analysis. Methods Enzymol 381: 715-735

Polerecky L (2005) Imaging of oxygen and pH in 2D and 3D using the MOLLI system. Available at: www.mpibremen.de/Lubos_Polerecky.html

Polerecky L, Franke U, Werner U, Grunwald B, de Beer D (2005) High spatial resolution measurement of oxygen consumption rates in permeable sediments. Limnol Oceanogr Methods 3:75-85

Polerecky L, Volkenborn N, Stief P (2006) High temporal resolution oxygen imaging in bioirrigated sediments. Environ Sci Technol 40:5763-5769

Polerecky L, Bissett A, Suci P, Stoodley P, de Beer D (2007) Mobile system for spectral imaging of reflectance and fluorescence from environmental samples at various spatial scales. Poster: B140, Proc Am Soc Microbiol Conf, Biofilms 2007, Quebec City, p 25-29

> Popa R, Weber PK, Pett-Ridge J, Finzi JA and others (2007) Carbon and nitrogen fixation and metabolite exchange in and between individual cells of Anabaena oscillarioides. ISME J 1:354-360

Precht E, Franke U, Polerecky L, Huettel M (2004) Oxygen dynamics in permeable sediments with wave-driven pore water exchange. Limnol Oceanogr 49:693-705

Ralph PJ, Schreiber U, Gademann R, Kühl M, Larkum AWD (2005) Coral photobiology studied with a new imaging PAM fluorometer. J Phycol 41:335-342

Ralph PJ, Macinnis-Ng CMO, Frankart C (2005b) Fluorescence imaging application: effect of leaf age on seagrass photokinetics. Aquat Bot 81:69-84

Revsbech NP (2005) Analysis of microbial communities with electrochemical microsensors and microscale biosensors. Methods Enzymol 397:147-166

Revsbech NP, Jørgensen BB (1983) Photosynthesis of benthic microflora measured with high spatial resolution by the oxygen microprofile method: capabilities and limitations of the method. Limnol Oceanogr 28:749-756

Revsbech NP, Jørgensen BB (1986) Microelectrodes: their use in microbial ecology. Adv Microb Ecol 9:293-352

Roff G, Ulstrup KE, Fine M, Ralph PJ, Hoegh-Guldberg O (2008) Spatial heterogeneity of photosynthesis in coral disease-like syndromes from the Great Barrier Reef. J Phycol 44:526-536

Roldán M, Thomas F, Castel S, Quesada A, HernándezMariné M (2004) Noninvasive pigment identification in living phototrophic biofilms by confocal imaging spectrophotometry. Appl Environ Microbiol 70:3745-3750

Schreiber U (2005) Pulse-amplitude (PAM) fluorometry and saturation pulse method. In: Papageorgiou G, Govindjee (eds) Chlorophyll fluorescence: a signature of photosynthesis. Advances in photosynthesis and respiration series. Kluwer Academic Publishers, Dordrecht, p 279-319

Schreiber U, Hormann H, Neubauer C, Klughammer C (1995) Assessment of photosystem II photochemical quantum yield by chlorophyll fluorescence quenching analysis. Aust J Plant Physiol 22:209-220

> Schreiber U, Kühl M, Klimant I, Reising H (1996) Measurement of chlorophyll fluorescence within leaves using a modified PAM fluorometer with a fiber-optic microprobe. Photosynth Res 47:103-109

Schröder CR, Polerecky L, Klimant I (2007) Time-resolved $\mathrm{pH} / \mathrm{pO}_{2}$ mapping with luminescent hybrid sensors. Anal Chem 79:60-70

Schultz RA, Nielsen T, Zavaleta JR, Ruch R, Wyatt R, Garner HR (2001) Hyperspectral imaging: a novel approach for microscopic analysis. Cytometry 43:239-247

Simon-Blecher N, Achituv Y, Malik Z (1996) Effect of epibionts on the microdistribution of chlorophyll in corals and its detection by fluorescence spectral imaging. Mar Biol 126:757-763

Smith GM, Thomson AG, Möller I, Kromkamp JC (2004) Using hyperspectral imaging for the assessment of mudflat surface stability. J Coast Res 20:1165-1175

Stahl H, Glud A, Schröder CR, Klimant I, Tengberg A, Glud R (2006) Time-resolved $\mathrm{pH}$ imaging in marine sediments with a luminescent planar optode. Limnol Oceanogr 4:336-345

Thar R, Kühl M, Holst G (2001) A fiber-optic fluorometer for microscale mapping of photosynthetic pigments in microbial communities. Appl Environ Microbiol 67:2823-2828

Vermaas WF, Timlin JA, Jones HD, Sinclair MB and others (2008) In vivo hyperspectral confocal fluorescence imaging to determine pigment localization and distribution in cyanobacterial cells. Proc Natl Acad Sci USA 105: 4050-4055

Volkenborn N, Polerecky L, Hedtkamp SIC, van Beusekom 
JEE, de Beer D (2007) Bioturbation and bioirrigation extend the open exchange regions in permeable sediments. Limnol Oceanogr 52:1898-1909

Vopel K, Hawes I (2006) Photosynthetic performance of benthic microbial mats in Lake Hoare, Antarctica. Limnol Oceanogr 51:1801-1812

Ward DM, Bateson MM, Ferris MJ, Kühl M, Wieland A, Koeppel A, Cohan FM (2006) Cyanobacterial ecotypes in the microbial mat community of Mushroom Spring (Yellowstone National Park, Wyoming) as species-like units linking microbial community composition, structure and function. Philos Trans R Soc Lond B 361:1997-2008

Wenzhöfer F, Glud RN (2004) Small-scale spatial and temporal variability in coastal benthic $\mathrm{O}_{2}$ dynamics: effects of fauna activity. Limnol Oceanogr 49:1471-1481

Werner U, Billerbeck M, Polerecky L, Franke U, Huettel M, van Beusekom JEE, de Beer D (2006) Spatial and temporal patterns of mineralization rates and oxygen distribution in a permeable intertidal sand flat (Sylt, Germany). Limnol Oceanogr 51:2549-2563

Submitted: April 9, 2008; Accepted: July 22, 2008
Wieland A, van Dusschoten D, Damgaard LR, de Beer D, Kühl M, Van As H (2001) Fine-scale measurement of diffusivity in a microbial mat with NMR imaging. Limnol Oceanogr 46:248-259

Wolfbeis OS (2003). A review on milestones in opt(r)ode technology until the year 2000. In: Narayanaswamy R, Wolfbeis OS (eds) Optical sensors for industrial, environmental and clinical applications. Springer, Berlin, p 1-34

Wolfbeis OS (2004) Fiber optic chemical sensors and biosensors. Anal Chem 76:3269-3283

Wolfbeis OS (2005) Materials for fluorescence-based chemical sensors. J Mater Sci 15:2657-2669

Zhu Q, Aller RC, Fan Y (2005) High-performance planar pH fluorosensor for two-dimensional $\mathrm{pH}$ measurements in marine sediment and water. Environ Sci Technol 39:8906-8911

Zhu Q, Aller RC, Fan Y (2006) A new ratiometric, planar fluorosensor for measuring high resolution, two-dimensional $\mathrm{pCO}_{2}$ distributions in marine sediments. Mar Chem 101:40-53

Proofs received from author(s): August 15, 2008 